This item was submitted to Loughborough's Research Repository by the author.

Items in Figshare are protected by copyright, with all rights reserved, unless otherwise indicated.

\title{
View it in a different light: Mediated and moderated effects of dim warm light on collaborative conflict resolution
}

PLEASE CITE THE PUBLISHED VERSION

https://doi.org/10.1016/j.jenvp.2017.04.007

\section{PUBLISHER}

(C) Elsevier

\section{VERSION}

AM (Accepted Manuscript)

\section{PUBLISHER STATEMENT}

This work is made available according to the conditions of the Creative Commons Attribution-NonCommercialNoDerivatives 4.0 International (CC BY-NC-ND 4.0) licence. Full details of this licence are available at: https://creativecommons.org/licenses/by-nc-nd/4.0/

\section{LICENCE}

CC BY-NC-ND 4.0

\section{REPOSITORY RECORD}

Kombeiz, Olga, Anna Steidle, and Erik Dietl. 2019. "View It in a Different Light: Mediated and Moderated Effects of Dim Warm Light on Collaborative Conflict Resolution”. figshare. https://hdl.handle.net/2134/36464. 


\title{
LIGHT AND CONFLICT RESOLUTION
}

View it in a different light: Mediated and moderated effects of dim warm light on collaborative conflict resolution.

\author{
Olga Kombeiz ${ }^{\mathrm{a}}$, Anna Steidle ${ }^{\mathrm{b}}$, Erik Dietl ${ }^{\mathrm{a}}$ \\ ${ }^{a}$ University of Hohenheim, Stuttgart, Germany \\ ${ }^{\mathrm{b}}$ Ludwigsburg University of Applied Sciences, Ludwigsburg, Germany
}

Manuscript accepted for publication in

Journal of Environmental Psychology - April 2017

\begin{abstract}
The manuscript may not exactly replicate the final version published in the journal. It is not the copy of record. The final article will be available, upon publication, via its DOI:
\end{abstract}

Kombeiz, O., Steidle, A., \& Dietl, E. (2017). View it in a different light: Mediated and moderated effects of dim warm light on collaborative conflict resolution. Journal of Environmental Psychology, 51, 270-283. https://dx.doi.org/10.1016/j.jenvp.2017.04.007

Acknowledgements

This paper is based on research conducted as a part of doctoral studies by the first author and supervised by the second author. The research was funded by Gips-Schüle Stiftung (www.gips-schuele-stiftung.de) at the graduate program people inside (www.peopleinside.de). The authors would like to express their gratitude to Konrad Senf for his insightful comments on a previous draft of this paper. We also thank our student assistants for their help in collecting data. Correspondence concerning this article should be directed to: Olga Kombeiz, Business and Organizational Psychology, University of Hohenheim, Wollgrasweg 49, 70599 Stuttgart, Germany, E-mail: okombeiz@ gmail.com. 


\section{LIGHT AND CONFLICT RESOLUTION}

Abstract

How can the physical environment, especially light, facilitate conflict resolution? Previous research has led to no clear answers about optimal lighting conditions in conflict situations and, until now, potential moderators and mediators have been scarcely investigated. Building on research on light-induced cooperativeness, we expected that self-oriented individuals would be influenced by the lighting in social situations such as conflict resolution. In selforiented individuals, dim warm light should promote interdependent self-construal and, in turn, lead to a preference for collaborative conflict resolution strategies. Two studies confirmed our assumptions, with social dominance orientation and trait interdependent selfconstrual serving as indicators of individuals' social orientation. Overall, these results provide an explanation for inconsistent previous findings and contribute to the understanding of lightinduced changes in social behavior. Limitations as well as practical implications for lighting design in social spaces are discussed.

Keywords: light, brightness, color temperature, conflict resolution strategies, social dominance orientation, interdependent self-construal

\section{Highlights:}

- Personality traits moderate the effect of dim warm light in conflict situations

- Dim warm light promotes situative interdependence orientation (self-construal)

- Dim warm light promotes collaborative conflict resolution via self-construal

- The effects emerge only for individuals with high social dominance orientation

- The effects emerge only for individuals with low interdependence orientation 


\section{LIGHT AND CONFLICT RESOLUTION}

\section{Introduction}

Driving a hard bargain or yielding to an opponent's demands in a business negotiation? Obliging one's partner's vacation plans, asserting one's own wishes, or finding a compromise? Avoiding a confrontation with one's children regarding tidying up or negotiating an integrative solution? In all these situations and decisions, people can either pursue only their own interests or take into account others' wishes. It all depends on how they view the situation and their relationship with the other individual. Research from the areas of grounded cognition and environmental psychology indicates that environmental features such as lighting conditions (e.g., Baron, Rea, \& Daniels, 1992; Knez, 1995; Steidle, Hanke, \& Werth, 2013) and room temperature (e.g., Gockel, Kolb, \& Werth, 2014; IJzerman \& Semin, 2009) can influence social perception. Thus, it should be of particular interest to examine how light affects interpersonal processes, especially concerning conflict resolution. Although a study (Baron, et al., 1992) has shown significant effects of lighting conditions on the preference for certain conflict resolution strategies, using another measure of conflict resolution strategies in the same study did not replicate these findings. To clarify these inconsistent results, the present research investigated a cognitive process (self-construal) that may explain why some light settings are able to promote collaborative conflict resolution. Moreover, we focused on a possible moderator (social orientation) to enhance the understanding of preconditions that limit the emergence of the light-conflict resolution link (see Figure 1 for the hypothesized model). This knowledge could contribute to the creation of collaborative work environments, in which light is always present, but its influence seldom considered.

Conflict resolution strategies have been widely researched in social (Pruitt, 1998) and organizational psychology (e.g., Rahim \& Bonoma, 1979; Ross \& Stittinger, 1991). During conflict resolution, individuals can focus on their own interests, the other person's interests, or 


\section{LIGHT AND CONFLICT RESOLUTION}

both, which yields five strategies (Rahim \& Bonoma, 1979; Rahim, 1983): integrating (problem solving by exchanging information, looking for alternative solutions and aiming to reach a mutually acceptable solution), obliging (playing down the differences between two parties and accentuating commonalities), compromising style (a "give-and-take" strategy where both partners have to give up something to reach a decision that is acceptable for both), dominating (a win-lose orientation and rejection of needs and expectations of the other party), and avoiding (withdrawal). Integrating, obliging, and compromising incorporate at least some inclination to consider the interests of others, while dominating and avoiding are associated with a low regard for others' interests. Hence, the former three strategies can be interpreted as collaborative and the latter two as non-collaborative (Chanin \& Schneer, 1984; Volkema \& Bergmann, 1995).

Baron et al. (1992) have directly tested the effect of lighting conditions on conflict resolution strategies. It was assumed that lighting conditions induce positive affect, which in turn should promote a preference for collaborative conflict strategies. In their laboratory studies, Baron et al. (1992) varied lighting in terms of illuminance level (150 vs. 1500 lx) and color temperature (warm white vs. cool white). Participants exposed to warm white light reported stronger preferences for conflict resolution through collaboration (i.e., integration) and weaker preferences for conflict resolution through avoidance than those exposed to cool white light. The preference for the non-collaborative avoidance strategy was lowest in the dim warm light condition. In contrast to these light-induced changes in general preferences for collaboration, light did not lead to more lenient responses to a colleague who failed on a work task for different reasons in a scenario that served as an additional measure of conflict resolution strategies. However, Baron et al. (1992) did not directly test the mediation effect via positive affect. Thus, these findings allow no clear conclusions about which lighting conditions may promote collaborative conflict resolution or about the underlying process. 


\section{LIGHT AND CONFLICT RESOLUTION}

Instead of investigating positive affect to explain the effect of light on conflict resolution, we focus on the effects of light that may occur without changing the emotional state (Friedman, Fishbach, Förster, \& Werth, 2003). Light largely determines how we perceive a room and its atmosphere (Custers, De Kort, IJsselsteijn, \& De Kruiff, 2010; Flynn, 1992), and this induces automatic assessments of the required behavior in a given situation. Hence, lighting conditions may well affect how individuals interpret a social situation and their resulting interpersonal behavior. Previous research showed that light can elicit a cozy and informal atmosphere, which should facilitate contact and openness among individuals. For example, one study showed that dimly lit rooms appear more intimate, relaxing, and romantic, and less tense, friendly, and threatening than brightly lit rooms (Custers et al., 2010). In addition to brightness, the warmth of the light affects its meaning: warm light creates a relaxing and cozy room atmosphere compared to neutral white (Theiss, 2000) and cold white light (Vogels, de Vries, \& van Erp, 2008), which appears rather cool and formal. Particularly, the combination of relatively low color temperature (about $3000 \mathrm{~K}$ ) and low illuminance levels (about 150 lx) creates a cozy and relaxing room ambience (Kuijsters, Redi, de Ruyter, Seuntiëns, \& Heynderickx, 2015).

Thus, we believe that there is a range of warm light on low until very low light intensity that may evoke associations of informality, intimacy, and coziness. However, the interpretation of the room atmosphere depends on further situational and individual characteristics. For instance, individuals may interpret dim warm light as cozy and intimate for social interactions, but as exhausting and confusing for activities requiring high concentration. As conflict resolution represents situations with social interaction, we assume that the intimacy, informality, and coziness of dim warm light, as compared to other combinations of brightness and color temperature, would promote interpersonal closeness and, in turn, collaborative conflict resolution. 


\section{LIGHT AND CONFLICT RESOLUTION}

However, to understand the emergence of the light-conflict resolution link, it is important to consider the underlying mechanism and potential limiting conditions. Visual messages of the light exert their influence via concomitant cognitive and motivational processes (Steidle et al., 2013; Steidle \& Werth, 2013). Self-construal represents an orientation towards interdependence which is sensitive to small variations in light (Steidle et al., 2013) and temperature (IJzerman \& Semin, 2009), and can help to explain light-induced changes in social behavior. In line with this assumption, several studies revealed that dim and warm light can positively influence person perception and social interaction. For instance, one study (Baron et al., 1992) showed that dim light (150 lx) led to more favorable person evaluations than bright light (1500 lx), while warm white light resulted in more helping behavior than cool white light. Additionally, dim light promoted cooperativeness (Steidle et al., 2013) and intimate communication (Gifford, 1988). Similarly, individuals preferred low brightness in informal and social situations (e.g., romantic; Biner, Butler, Fischer, \& Westergren, 1989). Moreover, other environmental cues of warmth or coldness (e.g., room temperature) also influence social proximity and affiliation (IJzerman \& Semin, 2009; Inagaki \& Eisenberger, 2013). Thus, due to the reported direct effects (Baron et al., 1992) and the indirect links between dim warm light and a cozy atmosphere, intimacy associations, as well as positive social interactions, we assume that that dim warm light may promote interdependent self-construal.

Generally, self-construal distinguishes two ways of representing oneself in relation to other individuals (Cross, Hardin, \& Gercek-Swing, 2011; Markus \& Kitayama, 1991): independent ('I') and interdependent ('we'). Independent self-construal is related to defining oneself as being apart from others (e.g., being exceptionally creative) and as a unique person with reference to stable internal traits (e.g., ambition). In contrast, interdependent self- 


\section{LIGHT AND CONFLICT RESOLUTION}

construal is related to defining oneself in terms of group memberships (e.g., Asian) and to view the self as encompassing important relationships (e.g., as a friend).

Self-construal also affects conflict resolution. According to Ting-Toomey (1988), connection to others may result in additional effort for the maintenance of group harmony and high concern for others. A person with high interdependent self-construal would rather cooperate to achieve the goals of both parties than endanger the harmony of the group. In line with this idea, two studies showed that independent self-construal ('I') is positively related to a non-collaborative strategy of dominating, while interdependent self-construal ('we') is positively associated with collaborative strategies of integrating, compromising, and obliging (Oetzel, 1998; Oetzel, Meares, Myers, \& Lara, 2003). In line with Rahim's conceptualization (Rahim, 1983; Rahim \& Bonoma, 1979), integrating was related to both self- and otherconcerns in one study (Oetzel, 1998). In contrast, avoidance showed an unexpected, inconsistent correlation pattern: it was positively related to interdependent self-construal, but only in one study (Oetzel, 1998). Previous studies indicate that contextual cues eliciting interdependent self-construal promote collaborative behavior. For instance, individuals primed with interdependent self-construal were more likely to surrender their own interests to those of the group than those primed with independent self-construal (Gardner, Gabriel, \& Lee, 1999). Moreover, Steidle et al. (2013) showed that participants were more likely to include others into their self (interdependent self-construal) at dim compared to bright lighting conditions, which in turn increased participants' cooperativeness in a prisoner's dilemma game. Hence, interdependent self-construal may mediate the expected effects of dim warm light on collaborative conflict resolution.

Environment-behavior links depend on individual differences (e.g., Dijkstra, Pieterse, \& Pruyn, 2008; Steidle et al., 2013). As individuals differ in the way they perceive and construe social situations (Colbert, Mount, Harter, Witt, \& Barrick, 2004; Funder, 1991; Varnum, 


\section{LIGHT AND CONFLICT RESOLUTION}

Grossmann, Kitayama, \& Nisbett, 2010), stable social orientations may be important moderators of light-induced changes in self-construal and conflict resolution. As individuals with high collective concerns are known to view the self as interconnected and defined in terms of important relationships (Markus \& Kitayama, 1991; Triandis, 1989), their willingness to stay interconnected with others (e.g., by cooperation) should be stable and not affected by situational context. In line with this assumption, Steidle et al. (2013) showed in one study that the darkness-cooperation link depended on participants' social value orientations. Only those high in individualistic orientation cooperated more in dim than in bright light, whereas the cooperativeness of those low in individualistic orientation was not affected by the lighting conditions. However, the role of self-construal was not tested in this study. Overall, we believe that the suggested light-induced changes in self-construal will only occur in self-oriented individuals.

Regarding the effects of lighting on self-construal and conflict resolution, two individual difference variables should be of particular relevance: trait self-construal as individuals' proclivity towards independent or interdependent self-construal (Cross et al., 2011) and social dominance orientation (SDO) as an individual's desire for dominance in social situations, including situations of social conflict (Pratto, Sidanius, \& Levin, 2006). Both trait interdependent self-construal (TSC) and SDO describe the perception of the self within a social context (Pratto et al., 2006; Singelis, 1994; Triandis, 1989). Whereas SDO refers to the basic attitude of superiority of one's own group over other relevant groups and affects social behavior towards other groups (Sidanius, 1993), TSC describes a general motivation to maintain group harmony (Ting-Toomey, 1988). Similar to low TSC, high SDO may generally provoke independent self-construal in situations of conflict resolution because SDO has been shown to be negatively associated with empathy for others and positively related to callousness (e.g., Altemeyer, 1998; Duckitt, Wagner, du Plessis, \& Birum, 2002). 


\section{LIGHT AND CONFLICT RESOLUTION}

Hence, we believe that the light-induced changes in self-construal and its consequences for conflict resolution may only emerge for self-oriented individuals (low in interdependent TSC and/or low in SDO), while other-oriented individuals may not be affected by lighting conditions. Following this argumentation, individual differences in social orientation should moderate the effects of dim warm light on self-construal (direct effect) and on conflict resolution (indirect effect).

\subsection{Overview of the present research}

The aim of this research was to clarify the effects of lighting on conflict resolution. Based on the idea that lighting conditions may influence individuals' interpretation of social situation and in line with previous research, we expected that the relation between dim warm light and situative interdependent self-construal would be moderated by social orientation. At low levels of social orientation, (a) high social dominance orientation and (b) low trait interdependent self-construal, there would be a positive relation between dim warm light and situative interdependent self-construal (Hypothesis 1). Moreover, we hypothesized that situative interdependent self-construal would be positively related to the collaborative conflict resolution strategies, (a) compromising, (b) obliging, and (c) integrating (Hypothesis 2).

Integrating $\mathrm{H} 1$ with $\mathrm{H} 2$, we hypothesized that the indirect effects of dim warm light on collaborative conflict resolution strategies via interdependent self-construal would be conditional on (i.e., moderated by) social orientation (H3), yielding a first-stage moderated mediation (Edwards \& Lambert, 2007). This hypothesis was tested with SDO as an indicator of social orientation in Study 1 and with TSC and SDO as indicators of social orientation in

Study 2. The proposed set of hypotheses provides a novel and parsimonious explanation for the rather inconsistent effects of lighting conditions on conflict resolution. Moreover, the present studies test for the first time whether changes in self-construal mediate the interactive effects of dim warm light and social orientation on collaborative behavior. 


\section{LIGHT AND CONFLICT RESOLUTION}

To test the generalizability of the effects and to allow practical implications (Highhouse, 2009; Thau, Pitesa, \& Pillutla, 2011), the effect of light on preferences for collaborative conflict resolution strategies was tested at different combinations of illuminance levels and color temperature in the two studies. Most laboratory studies use rather extreme settings, which maximizes the likelihood of significant effects. However, some of these extreme lighting settings do not conform to the actual lighting standards (EN 12464/ISO 8995) and can hardly be found in field situations. Hence, in Study 1, we aimed at simulating realistic office conditions. To allow comparisons with previous studies, more extreme lighting settings were used in Study 2.

Furthermore, it has been previously proposed that light may induce positive affect, which in turn leads to more prosocial behavior (Baron et al., 1992). This notion of lightinduced positive affect and its significance for collaboration has received mixed support (e.g., Baron et al., 1992; Knez, 1995; Knez, 2001; aan het Rot, Moskowitz, \& Young, 2008). In order to rule out this alternative explanation, we controlled for mood and satisfaction with lighting condition in both studies.

\section{Study 1}

\subsection{Method}

\subsubsection{Participants}

One hundred and five German undergraduates ( 74 females and 31 males; mean age $=$ 22.83 years; $S D=4.87$ ) were recruited via university mailing lists and took part in exchange for course credit or for a payment of $€ 10$. Participants were randomly assigned to one of the four lighting conditions. We calculated our target sample size for the interaction hypothesis using an estimated small to medium effect size, $f^{2}$ of 0.09 (see also, Bing, LeBreton, Davison, Migetz, \& James, 2007), which would require a sample size of approximately 103 participants 


\section{LIGHT AND CONFLICT RESOLUTION}

for the study to be powered at $90 \%{ }^{1}$. Sample sizes for specific analyses vary due to missing data on specific conflict scales from $\mathrm{N}=100-105$.

\subsubsection{Setting and procedure}

The experiment was conducted at [location masked for blind review] in a room that was designed for office work and contained regular office furniture: four desks and chairs, a monitor and a keyboard on each desk, which were positioned in a way that allowed no reflections and glare for the participants sitting at the desk. The walls and the ceiling were white and the carpeted floor was dark grey. The size of the room was $4.7 \mathrm{~m} \mathrm{x} 4.32 \mathrm{~m}$, and $2.35 \mathrm{~m}$ high. The windows were covered with blinds to ensure standardized artificial lighting conditions. The light was offered through six ceiling fluorescent light-based luminaires $\left(\mathrm{R}_{\mathrm{a}}=\right.$ 80), $149.5 \mathrm{~cm}$ (length) x $20 \mathrm{~cm}$ (width) each, with a digital switching function. The luminaires were set to create either bright (1000 lx) or dim (300 lx) lighting conditions, combined with either neutral white $(4200 \mathrm{~K})$ or warm white $(2800 \mathrm{~K})$ color temperature (see Figure 2$)$. Previous studies contrasting dim and bright lighting conditions used more extreme illuminance levels. The present study aimed to simulate realistic office lighting and therefore narrowed the range of the investigated illuminance level down to 300 to 1000 lux and varied the color temperature between warm (2800 K) and neutral (4200), because according to Kruithof (1941) the combinations of illuminance and color temperature in this area are perceived as more natural and comfortable. Thus, the four lighting conditions were: bright neutral $(1000 \mathrm{~lx}, 4200 \mathrm{~K} ; \mathrm{x}=.36, \mathrm{y}=.38)$, bright warm $(1000 \mathrm{~lx}, 2800 \mathrm{~K} ; \mathrm{x}=.45, \mathrm{y}=.43)$, $\operatorname{dim}$ neutral $(300 \mathrm{~lx}, 4200 \mathrm{~K} ; \mathrm{x}=.37, \mathrm{y}=.38)$ and $\operatorname{dim} \operatorname{warm}(300 \mathrm{~lx}, 2800 \mathrm{~K} ; \mathrm{x}=.44, \mathrm{y}=$ .42). As artificial lighting may produce uncomfortable heat stress (Hygge \& Knez, 2001),

particularly in the bright lighting conditions, the room temperature was held constant at $23{ }^{\circ} \mathrm{C}$ using an air conditioning system. 


\section{LIGHT AND CONFLICT RESOLUTION}

On the day before the experimental sessions, participants received an email requesting them to respond to an online survey assessing several personality traits. Individuals participated in groups of up to four individuals and were guided by an instructor. Upon arrival, one of the four lighting conditions was already present. Participants were seated in front of a computer, approximately $60 \mathrm{~cm}$ from the screen, facing the wall. They completed several questionnaires and worked on different tasks for one hour, providing information such as their current mood and satisfaction with the lighting condition, as well as their situative self-construal and conflict styles. At the end, participants indicated their sex and age, were thanked, and fully debriefed.

\subsubsection{Measures}

2.1.3.1. Collaborative conflict resolution strategy. To assess participants' inclinations towards different conflict resolution strategies, participants were requested to read through a scenario describing a business negotiation with a fictitious interaction partner and to assess how they would solve the presented conflict. To enhance generalizability, we used different scenarios. Based on a pilot study, three scenarios were selected which elicited similar conflict resolution strategies: (1) buying a used car from a salesman, (2) selling a used car to a potential customer, and (3) negotiating hiring conditions as a trade union member (for details, see supplementary material). Due to time constraints, each participant answered one randomly assigned negotiation scenario.

After reading through the scenario, participants filled out the German version of the conflict inventory (Rahim, 1983; Bilsky \& Wülker, 2000). Participants rated 15 questions about their preferred behavior in the respective scenario (e.g., "During the negotiation, I would use 'give and take' so that a compromise can be made") on a five-point Likert-type scale (1: strongly disagree -5 : strongly agree). Three items represented each of the five interpersonal conflict strategies: integrating, compromising, obliging, dominating, and 


\section{LIGHT AND CONFLICT RESOLUTION}

avoiding. As different scholars proposed different taxonomies of conflict resolution strategies, varying between two and five styles (Putnam \& Wilson, 1982; Pruitt, 1983; Thomas, 1976; Tjosvold, 1990), we conducted an exploratory factor analysis, which extracted four factors (compromising and integrating loaded on the same factor; see Table 1 for factor loadings). Consistent with these findings, confirmatory factor analyses showed that a four-factor model with four conflict strategies (compromising and integrating combined, alongside the remaining three styles) fits the data well $\left(\chi^{2}(51, N=98)=109.28, p=.033 ; \chi^{2} / d f=2.14, \mathrm{CFI}\right.$ $=.93, \mathrm{TLI}=.91, \mathrm{RMSEA}=.055, \mathrm{SRMR}=.075)$. According to $\mathrm{Hu}$ and Bentler $(1999), \mathrm{CFI}$ and TLI values close to .95 , RMSEA values smaller than .06 and SRMR values close to .08 suggest an acceptable fit. All items and facets had significant factor loadings on intended factors, except for one item of avoiding $(p=.10)$. However, the avoiding conflict strategy was not a focal variable of this research, and the overall model fit was good. Hence, four conflict resolution strategies were computed: cooperating (items of the subscales integrating and compromising; $\alpha=.79)$, obliging $(\alpha=.46)$, dominating $(\alpha=.75)$, and avoiding $(\alpha=.54)$. Internal consistencies were similar to those reported in previous studies (e.g., Boyce et al., 2003). To avoid biases due to differences in the conflict resolution strategies between the three scenarios, the conflict resolutions strategies were $\mathrm{z}$-standardized per scenario ${ }^{2}$.

\subsubsection{Situative self-construal. The situative self-construal in the conflict scenario was} measured by the Inclusion of the Other in the Self scale (IOS; Aaron, Aaron, \& Smollan, 1992). This scale consists of seven different overlapping pairs of circles that describe the relationship between the participant and the negotiation partner. Participants selected one of the seven pictures, representing a 7-point scale. Higher values indicate a higher perception of affiliation with the interaction partner and can be interpreted as situative interdependent selfconstrual (Steidle et al., 2013). 


\section{LIGHT AND CONFLICT RESOLUTION}

2.1.3.3. Social dominance orientation (SDO). Participants assessed their social dominance orientation $(\alpha=.84)$ with the German version of the SDO-questionnaire (Cohrs, Kielmann, Moschner, \& Maes, 2005; Jost \& Thompson, 2000). The SDO-questionnaire contains 12 selfreport items with a response scale ranging from 1 (strongly disagree) to 7 (strongly agree). Sample items include "Some groups of people are just more worthy than others" and "All groups should be given an equal chance in life" (reversed). The distribution of the participants between dim warm lighting and the control conditions regarding SDO was acceptable $(t$ (103) $=.02, p=.98)$.

2.1.3.4. Control variables. Previous research has proposed that light may elicit positive affect, which in turn fosters collaboration (e.g., Baron et al., 1992; Knez, 1995; Knez, 2001). In order to control for this alternative explanation, we assessed mood as a general indicator of positive emotions and "satisfaction with lighting" as an indicator of positive affect associated with the light. Mood ( $\alpha=.89$ ) was measured using Nitsch's four-item Personal State Scale (Apenburg, 1986; Nitsch, 1976), which employs ratings ranging from 1 (strong rejection) to 9 (strong agreement). Satisfaction with the light $(\alpha=.86)$ was assessed with two items answered on a seven-point scale 1 (strongly disagree) to 7 (strongly agree): "The lighting is pleasant" and "I am satisfied with the lighting condition".

\subsection{Results}

\subsubsection{Analytic Strategy}

We tested the moderation hypotheses using the moderated regression procedures recommended by Aiken and West (1991). We centered all lower-order terms involved in the hypothesis testing and then multiplied them to create interaction terms. The focal warm dim lighting was represented by a dummy variable ( $\operatorname{dim}$ warm $=1$, other lighting conditions $=0$ ). As all lighting conditions represented different manipulations, we included two additional dummy variables in all analyses: bright neutral light (bright neutral light $=1$, other conditions 


\section{LIGHT AND CONFLICT RESOLUTION}

$=0$ ) and bright warm light (bright warm light $=1$, other conditions $=0$ ). As our research question focused on the effect of the combination of warm and dim light, the other three lighting conditions served as equally important control conditions. In order to represent all four lighting conditions (Cohen, Cohen, West, \& Aiken, 2003), two randomly chosen dummy variables served as control variables in the analyses. We conducted OLS mediation analyses using a bias-corrected bootstrapping procedure with 10,000 bootstraps to test our moderated mediation hypotheses (Hayes, 2013). Importantly, moderated mediation does not provide an interpretation for a single direct or indirect effect of $\mathrm{X}$ on $\mathrm{Y}$, because the effect is conditioned on the variable that moderates it (Hayes, 2013). The conditional indirect effect is significant if its confidence interval does not include zero (Hayes, 2013). As recommended by Bing et al., (2007), to increase statistical power, we used one-tailed tests for our interactions as they were predicted a priori. According to Preacher, Zyphur, and Zhang (2010), mediation hypotheses are directed hypotheses and therefore have to be tested on a one-tailed alpha level $\alpha=.05$, corresponding to a $90 \%$ confidence interval. Thus, the proposed conditional indirect effects would be confirmed if the $90 \%$ bias-corrected bootstrap confidence intervals did not include zero.

\subsubsection{Hypothesis Testing}

Table 2 presents descriptive statistics, correlations, and reliabilities of all variables. As expected, SDO moderated the effect of dim warm light on situative self-construal $(b=.90, p$ $=.007$, see Table 3 , Model 2) ${ }^{3}$. Plotting the interaction at low and high levels $(+/-1 S D$ from mean; Figure 3) of the moderator shows that the relationship between dim warm light and interdependent situative self-construal was positive and significant for individuals high in $\operatorname{SDO}(b=1.40, p=.002)$, but not for those low in SDO $(b=-.22, p=.32)$. Hence, H1 was supported. 


\section{LIGHT AND CONFLICT RESOLUTION}

Consistent with $\mathrm{H} 2$, situative self-construal was positively related to both collaborative conflict resolution strategies: cooperating $(r=.51, p=.00 ; b=.39, p=.00)$ and obliging $(r=$ $.20, p=.03 ; b=.18, p=.01$ ), in correlation and regression analyses (see Table 3, Models 34).

To test H3, we used model 7 of Hayes' (2013) PROCESS macro for SPSS and compared the conditional indirect effect of dim warm light on collaborative conflict styles via interdependent situative self-construal for SDO at $1 S D$ above the mean and at $1 S D$ below the mean. The results revealed that the indirect effect of dim warm light on the preference for cooperating via situative self-construal was significant for individuals high in SDO (indirect effect $=.54, S E=.21,90 \% C I[.25, .95])$ and for mean levels of SDO, but not for those low in SDO (indirect effect $=.02, S E=.18,90 \% C I[-.25, .36]$ ). Similarly, the indirect effect of dim warm light on the preference for obliging via situative self-construal was significant for individuals high in SDO (indirect effect $=.25, S E=.12,90 \% C I[.09, .51]$ ) and for mean levels of SDO, but not for those low in SDO (indirect effect on obliging = -.03, SE = .09, $90 \% C I[-.19, .09])$. Further, the index of moderated mediation on the preference for collaborative conflict resolution strategies in dim warm light were positive and their CIs did not include zero (see Table 4 for the complete results of moderated mediation analyses). Consequently, $\mathrm{H} 3$ was supported.

To test for potential biases, we repeated the analyses and separately included age, gender, satisfaction with light, and mood as covariates. The interaction effect in Model 2 and the conditional indirect effects in Models 3 and 4 remained significant after controlling for these variables (all $p \mathrm{~s}<.05$, CIs did not include zero). Hence, the reported effects cannot be attributed to differences in age, gender, satisfaction with light, or mood. Overall, these results confirm our assumption that dim warm light elicits interdependent self-construal for 


\section{LIGHT AND CONFLICT RESOLUTION}

individuals with high social dominance orientation and, in turn, promotes the likelihood of choosing collaborative conflict resolution strategies.

\section{Study 2}

Study 2 aimed at substantiating and extending the effects found in Study 1. We tested the same set of hypotheses. However, two alterations were made. First, in contrast to previous studies, Study 1 only used a very small variation of illuminance levels (300 vs. 1000 lx) and color temperature (2800 vs. $4200 \mathrm{~K}$ ), while previous studies (Baron et al., 1992, Knez, 2001; Steidle et al., 2013) used greater variation of brightness and color temperature. Hence, we aimed to substantiate the premise that the preference for collaborative conflict strategies in dim warm light depends not only on standard lighting conditions, but can also be generalized to the combination of brightness and color temperature in a very broad range. Thus, in line with previous studies (Baron et al., 1992, Knez, 2001; Steidle et al., 2013), a larger variation of brightness (150 vs. 1500 lx) and color temperature (2500 vs. 5500 K) was used in Study 2. Second, in Study 1, social dominance orientation served as an indicator of participants' social orientation. However, the important process revealed in Study 1 was the self-construal level, which mediated the effect of lighting conditions on the preference for conflict resolution strategies. Hence, to take a more direct approach, we additionally included trait interdependent self-construal as a measure of social orientation.

These alterations also allowed testing an alternative explanation of the trait-light setting interactions ${ }^{4}$. Building on cognitive dissonance theory (Festinger, 1957), the effect of dim warm light on self-construal might occur because individuals with high trait interdependent self-construal feel more consonant with the dim-warm light and follow their inclination to collaborate, whereas those with a low trait level other-orientation may feel more "dissonant and not at ease" in the dim-warm light and adapt their behavior to the given situation. This implies that the feeling of dissonance or consonance would be reflected in the 


\section{LIGHT AND CONFLICT RESOLUTION}

individuals' experience of the room, such as satisfaction with light and mood. We therefore tested for this alternative explanation.

\subsection{Method}

\subsubsection{Participants}

One hundred and fifty seven German students were recruited via university mailing lists and took part in exchange for course credit or for a payment of $€ 15$. Five participants were excluded from further analyses because they did not understand the survey questions (two individuals) and because of familiarity with the scenarios of conflict styles due to participation in a previous study (three individuals). Finally, data of one hundred and fifty two students ( 75 females and 77 males; mean age $=23.64$ years; $S D=5.69$ ) were used for statistical analyses. Participants were randomly assigned to one of the four lighting conditions. Sample sizes for specific analyses vary due to missing data on conflict strategies scales from $N=150-152$.

\subsubsection{Setting and procedure}

The experiment was conducted at the [location masked for blind review] as part of a larger research project on lighting effects on behavior. The size of the room was $5.10 \mathrm{~m}$ by $3.50 \mathrm{~m}$, and $3.00 \mathrm{~m}$ high, and the windows were covered with blinds. The light was supplied through 3 pendant ceiling LED light-based luminaires $\left(\mathrm{R}_{\mathrm{a}}=90\right), 116 \mathrm{~cm}$ (length) by $8.5 \mathrm{~cm}$ (width) each, with $50 \mathrm{~cm}$ distance from the ceiling (see Figure 4). The luminaires were set to produce either bright (1500 lx) or dim (150 lx) direct-indirect lighting, combined with either cold white $(5500 \mathrm{~K})$ or warm white (warm, $2500 \mathrm{~K})$ color temperature, yielding four lighting conditions labeled bright cold $(1500 \mathrm{~lx}, 5500 \mathrm{~K} ; \mathrm{x}=.33, \mathrm{y}=.35)$, bright warm $(1500 \mathrm{~lx}, 2500$ $\mathrm{K} ; \mathrm{x}=.47, \mathrm{y}=.42)$, dim cold $(150 \mathrm{~lx}, 5500 \mathrm{~K} ; \mathrm{x}=.33, \mathrm{y}=.36)$, and dim warm light $(150 \mathrm{~lx}$, $2500 \mathrm{~K} ; \mathrm{x}=.48, \mathrm{y}=.44)$. The participants worked on different tasks for one hour and 15 minutes. The additional setting arrangement and procedure was identical to Study 1 . 


\section{LIGHT AND CONFLICT RESOLUTION}

\subsubsection{Measures}

Conflict resolution strategies, situative self-construal, SDO, and control variables were assessed using the instruments described in Study 1. The distribution of the participants between dim warm lighting and control lighting conditions regarding SDO was acceptable $(t$ $(150)=0.32, p=.75)$.

As in Study 1, the confirmatory factor analysis revealed that a four-factor measurement model displayed a good fit to the data $\left(\chi^{2}(51, N=150)=112.92, p=.019 ; \chi^{2} / d f\right.$ $=2.21, \mathrm{CFI}=.92, \mathrm{TLI}=.90, \mathrm{RMSEA}=.048, \mathrm{SRMR}=.059)$ and all items had significant factor loadings on intended factors. Thus, we averaged the items of compromising and integrating into an overall cooperating score $(\alpha=.75)$, and all other items into their respective dimensions, obliging $(\alpha=.45)$, dominating ( $\alpha=.63)$, and avoiding $(\alpha=.49) .^{5}$

\subsubsection{Trait interdependent self-construal (TSC). TSC $(\alpha=.56)$ was assessed via the} German version of the Self-Construal Scale (Singelis, 1994) prior to the lab experiment. The reliability was comparable to previous studies (e.g., Escalas \& Bettman, 2005). The scale contains 12 self-report items with a response scale ranging from 1 (strongly disagree) to 7 (strongly agree). Sample items include "It is important for me to maintain harmony within my group" and "My happiness depends on the happiness of those around me". The distribution of the participants between dim warm lighting and control lighting conditions regarding TSC was acceptable $(t(150)=-0.88, p=.38)$.

\subsection{Results}

\subsubsection{Analytic Strategy}

We used the same analytic strategy as in Study 1. In the first step, we tested the interaction between dim warm light and SDO on situative self-construal, in the second step, the interaction effect of dim warm light and TSC on situative self-construal, and in the third step, both moderators at once: SDO and TSC (Model 2 of PROCESS; Hayes, 2013). 


\section{LIGHT AND CONFLICT RESOLUTION}

\subsubsection{Hypothesis Testing}

Table 5 presents descriptive statistics, correlations, and reliabilities of all variables. As expected, SDO moderated the effect of dim warm light on situative self-construal $(b=.39, p$ $=.03$, see Model 2a, Table 6). Plotting the interaction at low and high levels (+/- 1 SD from mean; Figure 5) of the moderator shows that the positive relationship between dim warm lighting and interdependent situative self-construal was only significant for individuals high in SDO $(b=.64, p=.04)$, but not for those low in this trait $(b=-.17, p=.32)$. Consistent with $\mathrm{H} 1$, interdependent TSC also moderated the effect of light on situative self-construal in dim warm lighting $(b=-.88, p=.01$, see Model $2 b$, Table 6). Plotting the interaction at low and high levels (+/- 1 SD from mean; Figure 6) of the moderator shows that the positive relationship between dim warm lighting and interdependent situative self-construal was only significant for individuals low in interdependent TSC $(b=.73, p=.02)$, but not for those high in this trait $(b=-.33, p=.19)$. Testing both moderators at once using Model 2 of Hayes' (2013) PROCESS macro, the interactive effect of TSC and dim warm light on situative selfconstrual remained significant $(b=-.69, p=.03)$, but the interactive effect of SDO and dim warm light was only marginally significant $(b=.31, p=.08)$. The incremental variance of $4.6 \%$ due to both interactions was significant $(p=.01$, see Model 2c, Table 6). These results support H1.

Consistent with $\mathrm{H} 2$, situative self-construal was positively related to the collaborative conflict resolution strategies: cooperating $(r=.19, p=.02 ; b=.15, p=.02)$ and obliging $(r=$ $.18, p=.02 ; b=.15, p=.02$ ), in correlation (see Table 5) and regression analyses (see Table 6, Models 3-6).

To test H3, we compared the conditional indirect effect of dim warm light on collaborative conflict resolution strategies via interdependent situative self-construal for SDO at $1 \mathrm{SD}$ above the mean and at $1 \mathrm{SD}$ below the mean. The results revealed indirect effects on 


\section{LIGHT AND CONFLICT RESOLUTION}

cooperating (indirect effect $=.09, S E=.08,90 \% C I[.002, .29]$ ) and on obliging (indirect effect $=.09, S E=.08,90 \% C I[.004, .30]$ via situative self-construal that were significant for high SDO, but not for low SDO (indirect effect on cooperating = -.02, SE =.06,90\% CI [-.14, .06]; indirect effect on obliging $=-.02, S E=.06,90 \% C I[-.14, .05])$ or for mean levels of SDO. Further, the index of moderated mediation on cooperating and obliging were positive and their CI did not include zero (see Table 7 for the results of moderated mediation analyses). In line with $\mathrm{H} 3$, the moderated mediation using TSC as moderator revealed that the indirect effects of dim warm light on cooperating (indirect effect $=.11, S E=.08,90 \% C I[.02$, $.29]$ ) and on obliging (indirect effect $=.11, S E=.07,90 \% C I[.03, .28]$ ) via situative selfconstrual were only significant for individuals low in interdependent TSC, but not for those high in interdependent TSC (indirect effect on cooperating $=-.05, S E=.06,90 \% C I[-.18$, $.02]$, indirect effect on obliging $=-.05, S E=.06,90 \% C I[-.18, .02])$, or for those with mean levels of TSC. Moreover, the index of moderated mediation on cooperating and obliging were negative and their CIs did not include zero (see Table 7). Consequently, H3 was supported.

To test an alternative explanation of the trait-light setting interactions, we conducted moderated regression analyses on participants' satisfaction with the light and on their mood, as described in the analytic strategy in Study 1. The dim warm dummy variables, social dominance orientation, and their interaction served as predictors; the bright warm and bright cold dummy variables were used as control variables. Results showed that TSC did not directly affect satisfaction with the dim warm light $(r=.08, p=.32)$ or $\operatorname{mood}(r=-.14, p$ $=.20$ ), nor did it moderate the effect of the dim warm condition on satisfaction with the light $(b=.06, p=.45)$ or on $\operatorname{mood}(b=-.52, p=.12)$. This speaks against the alternative explanation of feelings of dissonance or a fit between trait-related inclinations and environmental settings. 


\section{LIGHT AND CONFLICT RESOLUTION}

To test for potential biases, we repeated the analyses and separately included age, gender, satisfaction with light, and mood as covariates. The interaction effects in Models 2a$2 \mathrm{c}$ and the conditional indirect effects in Models 3 and 4 remained significant after controlling for age, gender, satisfaction with light, and $\operatorname{mood}($ all $p s<.05$, CIs did not include zero). Hence, the reported effects cannot be attributed to differences in age, gender, evaluation of lighting conditions, or mood. Overall, these results support our assumption that dim warm light elicits situative interdependent self-construal for individuals with low levels of trait interdependent self-construal and with high levels of social dominance orientation and, in turn, promotes a preference for collaborative conflict resolution strategies.

\section{Discussion}

Lighting conditions can shape the way some individuals see themselves and others, and thus influence the way they interact. In two studies, we investigated how brightness and warmth of light affect conflict resolution alongside mediating and moderating variables. Overall, the results revealed that self-oriented individuals were more likely to include their negotiation partner into the self in dim warm light than in other lighting conditions, which, in turn, promotes collaborative conflict resolution. Three moderation analyses showed that the effect of light on self-construal and, indirectly, on conflict resolution only emerged for individuals high in social dominance orientation and/or low in trait interdependent selfconstrual. Apparently, an individual's social orientation limits the potential of light to induce collaboration. The similarity in the moderation effects of two different measures assessing traits related to social orientations as well as the consistency of the effects across the two studies (smaller or greater variations of illuminance level and color temperature) suggest some generalizability of the reported effect. Changes in self-construal mediate the interactive effect of dim warm light and social orientation, while other explanations (mood and light 


\section{LIGHT AND CONFLICT RESOLUTION}

preference) could be rejected. Overall, we conclude that light can prompt self-oriented individuals to collaborate by inducing a sense of "we".

The present findings supplement previous research on the effects of the physical environment on social perception and behavior, and explain previous inconclusive findings. Environmental stimuli, such as illuminance levels (aan het Rot et al., 2008; Steidle et al., 2013; Zhong, Bohns, \& Gino, 2010) and color temperature (Baron et al., 1992), have been shown to impact social interaction, but the underlying processes as well as the limiting conditions of this effect, which could possibly explain inconsistent findings, are largely unknown. Hence, we first discuss how this research contributes to the understanding of the impact of lighting on social behavior. Moreover, if lighting conditions are able to foster social-supportive atmospheres, this has practical implications for architecture and the design of social spaces. Finally, the limitations of the research will be discussed.

\subsection{Research implications}

One major contribution of this research is that it helps to explain why previous research on the impact of lighting on conflict resolution yielded mixed findings (Baron et al., 1992). One study suggested that warm (and dim) light induced a general inclination towards collaboration in conflict situations (Baron et al., 1992), but this result was not replicated using a different measure of conflict resolution in the same study (Baron et al., 1992). However, in line with Baron's first result, our two studies clearly support the assumption that dim warm light may foster collaborative conflict resolution. The apparent inconsistency in the findings can be explained by three considerations.

First, our moderation analyses revealed that the light-conflict resolution link depended on individual differences. As in a previous study by Steidle et al. (2013) on cooperativeness in a prisoner's dilemma game, only individuals high in individualistic orientation were positively affected by the light. While social value orientation was conceptualized to explain 


\section{LIGHT AND CONFLICT RESOLUTION}

individual differences in cooperation in prisoner's dilemmas (Kuhlman \& Marshello, 1975), in the present research, we investigated two personality traits that are crucial in situations of conflict resolution (e.g., Derlega, Cukur, Kuang, \& Forsyth, 2002; Sidanius, 1993; TingToomey, Oetzel, \& Yee-Jung, 2001). SDO may affect a host of behavioral outcomes towards other groups and individuals in social situations (Sidanius, 1993), whereas TSC involves an emphasis on connectedness to others and results in a need for harmony (Ting-Toomey, 1988). Thus, both may explain individual differences in conflict situations. As these individual differences were not taken into account in the studies by Baron, the interaction effect may have been neglected.

Second, from the description in the article (Baron et al., 1992), it cannot be determined whether the presented conflicts provide an opportunity for mutual gains through collaboration. As discussed previously (Steidle et al., 2013), light-induced interdependent self-construal should lead to more collaboration and cooperation in situations in which mutual gains are possible (e.g., cooperative partner) but not when mutual gains are impossible (e.g., uncooperative partner). In the presented scenarios in our studies, participants imagined meeting a person willing to negotiate and could see gains for both sides from sealing the bargain. This presents a situation in which collaboration helps to reach individual and mutual goals, while it remains unclear whether the conflicts represented in previous studies offered this possibility. Overall, light-induced collaboration in conflict situations depends on multiple environmental, situational, and individual context factors.

The third important contribution is the interaction effect of light and an individual's stable social orientation on situative self-construal which has been shown, as far as we are aware, for the first time. As situative self-construal represents the underlying process leading to prosocial behavior and a previous study indicated an interaction effect between light and a trait of social orientation on cooperation (Steidle et al., 2013), these results provide a 


\section{LIGHT AND CONFLICT RESOLUTION}

consistent understanding of how and why individuals low in social orientation are influenced by light: dim warm light apparently does not directly influence collaborative behavior, but is instead an anteceding cognitive process, in particular in the construal of the social situation, of the self, and of others. Moreover, we explored an alternative explanation of trait-light setting interactions based on cognitive dissonance theory. In particular, it could be argued that selforiented individuals feel less consonant with the dim warm light and adapt their behavior to higher collaboration as a consequence of cognitive dissonance. However, in Study 2, trait interdependent-self construal did not directly affect the way participants experienced the room, such as in their satisfaction with the light or in terms of their mood, nor did it interact with dim warm light to predict these dependent variables. This finding speaks against the alternative explanation of trait-light interactions based on cognitive dissonance theory.

In this context, it is also important to consider that self-construal relates to a number of behavioral outcomes. For instance, activated interdependent self-construal has been shown to lead to negative evaluations of others' selfish behavior (Gardner et al., 1999) and to a preference for smaller spatial distance during an interaction (Holland, Roeder, van Baaren, Brandt, \& Hannover, 2004). Moreover, individuals with an independent (versus interdependent) self-construal tend to present themselves in terms of their individual skills and expertise (versus in terms of their social skills; Lalwani \& Shavitt, 2009) and show more verbal self-promotion (e.g., not admitting others' contributions to their own success; Ellis \& Wittenbaum, 2000). Furthermore, self-construal is related to context-specific risk-taking: activated interdependent self-construal results in high risk-seeking in financial contexts, but less risk-seeking in social contexts (e.g., potentially embarrassing situations; Mandel, 2003). Hence, via the activation of a situative interdependent self-construal, dim warm light may have indirect effects on impression management, self-disclosure, social risk-taking, and moral 


\section{LIGHT AND CONFLICT RESOLUTION}

judgment, especially for individuals low in social orientation. This may be a constructive area for future research.

\subsection{Future research}

Further research is also needed on the effects of other environmental features such as room temperature, as well as on interaction effects between light and other physical features, for instance, a room's temperature, space, or spatial layout. Due to the link between the experience of physical temperature and feelings of psychological warmth (IJzerman \& Semin, 2009, 2010; Bargh \& Shalev, 2011), room temperature can influence social perceptions (e.g., social exclusion; Zhong \& Leonardelli, 2008) and interpersonal behavior (e.g., customer orientation; Kolb, Gockel, \& Werth, 2012). In this context, the role of SDO and TSC is of particular interest. It might be expected that, similarly to the present findings, individuals with low SDO and high TSC scores would not be influenced by environmental features such as room temperature, because they always tend to have an orientation towards interdependence with others. Thus, a cold room could promote self-construal and, for example, customer orientation, only for individuals with high SDO or low TSC.

As real environments consist of many other lighting (e.g., accent light) and room aspects, it would be highly interesting to investigate the combined effect of light and other environmental features, such as room temperature, on social behavior. Would warm light reduce the feelings of loneliness and the associated affiliation motivation in a cold room, which would speak for a supplementary effect? Or would warm temperature and warm light, both of which promote the inclusion of others in the self, lead to additive or multiplicative effects on self-construal and social behavior of individuals high on social orientation? Similarly, space represents another important environmental condition in interactions, as all spatial and interpersonal distance dimensions are interrelated (Bar-Anan, Liberman, Trope, \& Algom, 2007). Consistently, interdependent self-construal is also linked to interpersonal 


\section{LIGHT AND CONFLICT RESOLUTION}

closeness (Lee, Draper, \& Lee, 2001). Thus, spatial proximity in the form of negotiation partners sitting close to one another could promote interpersonal proximity and boost the effect of dim warm light on interdependent self-construal for self-oriented individuals. As interesting as these ideas may be, they need to be tested before being recommended to or by practitioners.

Finally, as participants of the present studies were German, it would be interesting to investigate these effects in other cultures. Previous research showed that the range and mean values of SDO are similar in different countries, including in Asian samples (Pratto et al., 2000). However, other studies indicate cultural differences in TSC (Markus \& Kitayama, 1991), and in lighting preferences regarding combinations of brightness and color temperature (Park, Pae, \& Meneely, 2010). According to the study by Park et al. (2010), individuals in western cultures prefer warm light color at low intensity for informal activities (i.e., hotel guest rooms), whereas Asians prefer warm light color at high intensity. Thus, in other

cultures, bright and warm (instead of dim warm) light might be perceived as "social light" and should be investigated in further research. Moreover, due to the cultural differences in TSC (i.e., high orientation towards interdependence in Asians), the interaction effect between lighting condition and social orientation on self-construal might be absent. Thus, crosscultural comparisons are needed to be able to generalize the present findings to other cultures.

\subsection{Limitations}

The contributions of the present research should be qualified in light of its limitations. First, in the current studies, conflict resolution was measured in the form of questionnaires covering different conflict resolution strategies, but without observing actual behavior. Although the reported preferences for certain conflict resolution strategies produce consistent behavior in negotiations (e.g., Ajzen, 1991; Psenicka \& Rahim, 1989; Volkema \& Bergmann, 1995), it is necessary to investigate actual behavior in real negotiations to be able to 


\section{LIGHT AND CONFLICT RESOLUTION}

generalize the reported effects to real-world situations. Moreover, although three different conflict scenarios (both sides of a commercial transaction and a salary negotiation) were presented, there is an unlimited number of other potential conflicts in work settings that should be considered as well (e.g., interpersonal conflicts between colleagues, mobbing situations).

Second, the present findings did not answer the question what kind of lighting is optimal for collaboration. In addition to color temperature and illuminance levels, important features of artificial light comprise the spatial distribution of the light (uniformity), personal control over the lighting conditions, and the color of the light. In the present studies, we varied different combinations of brightness and color temperature using direct (Study 1) and direct-indirect (Study 2) light. Although direct and direct-indirect light lead to similar effects, we did not directly compare different spatial distributions and did not replicate the study using only indirect light. Similar to dim and bright light, individuals prefer non-uniform to uniform light for informal or social activities (Flynn, 1977; Kobayashi, Inui, \& Nakamura, 2001). Hence, non-uniformity may boost the positive effects of dim warm light on collaboration. In addition, personal control strongly impacts satisfaction with the light and subjective wellbeing (Flynn, 1977; Veitch, Newsham, Boyce, \& Jones, 2008), but Boyce, Veitch, Newsham, Myer, and Hunter (2003) reported no influence of personal control on conflict resolution strategies. Due to these considerations, it is also important to take into account the spatial distribution of the light (i.e., the proportion of direct and indirect lighting; accent vs. general lighting), as well as the user's perceived control in future research and applications on “collaborative light".

Third, although different levels of illuminance and color temperature have been used, we did not investigate the effect of variations in daylight on self-construal and conflictresolution strategies. However, reduced brightness has been shown to promote more positive 


\section{LIGHT AND CONFLICT RESOLUTION}

social evaluations in both artificial and natural light. Compared to a brightly lit room, participants in the study by Baron et al. (1992) assigned higher performance evaluations to a fictitious employee in a dim room. Similarly, cloudy weather (i.e., reduced natural brightness) led to more positive reactions by women to men's assured behavior in another study (Rauthmann, Kappes, \& Lanzinger, 2014). It may well be that the soft warm light of a sunset increases the likelihood of perceiving togetherness. However, more research is needed to answer these questions.

Fourth, it could be argued that the laboratory setting (with the conspicuous exclusion of daylight and the bare furnishing not being typical features of conventional European offices) and student participants (who lack the experience of working in offices) may reduce the generalizability of findings to real work contexts. However, as recently suggested in organizational research (Highhouse, 2009; Thau et al., 2011), experiments allow generalizations across organizations due to manipulation factors that are relevant to an "average" organizational context compared to observational studies in the context of a single organization or activity. Moreover, our student participants have typically completed at least one extensive internship at this stage of their studies and we believe that young adults are generally familiar with work environments: personally in the form of learning environments at schools and universities, and indirectly via the media. Furthermore, the test room in Study 1 was located in a building without lecture rooms and the test room in Study 2 was situated at a Research Institute, which does not belong to the university campus and comprises several office buildings. As for the sparsely furnished test rooms, new office forms such as open space offices are similarly free of clutter and personal belongings. Hence, overall, the test rooms should elicit the impression of a working environment (versus a private room) in the participants. However, field studies would certainly complement the present research. 


\section{LIGHT AND CONFLICT RESOLUTION}

Finally, in two studies, we found slightly different results in the conditional indirect effect for individuals with medium levels of social dominance orientation. The indirect effects on conflict resolution strategies were only observed in Study 1. These effects cannot be attributed to different variations of brightness or the color temperature of dim warm light, but rather depend on the correlation between self-construal and collaborative conflict strategies, which are high in Study 1 and moderate in Study 2. More importantly, the results for individuals with high and low levels of SDO are similar in both studies.

\subsection{Practical implications}

The current results also have practical implications that should be considered in light of the estimation of practical significance. Although the explained variance of the reported effects indicates small or medium effect sizes of interaction (5\% in study 1 , and between $2 \%$ and $5 \%$ in study 2), in the context of organizational psychology, it has repeatedly been shown that interaction effects typically feature small effect sizes because of the reduction of the product variance due to the multiplication of predictor and moderator variables (Bing et al., 2007; Champoux \& Peters, 1987; McClelland, \& Judd, 1993). Therefore, explained variance between $1 \%$ and 3\% should still be considered important (see Bing et al., 2007; Evans, 1985; McClelland, \& Judd, 1993). Building on these considerations, first ideas of applied solutions of these findings will be outlined.

When designing work places where collaboration is important (e.g., conference and meeting rooms in organizations, group learning spaces at schools and universities), lighting should be taken into account. It may not be enough to install lights that meet the requirements specified by the regulations or to simply opt for the brightest or most energy-efficient solutions. Dim warm light or dynamic light with the option to set "collaborative light" in such rooms could contribute to cooperative decisions and discussions. Independent of the occasion, 


\section{LIGHT AND CONFLICT RESOLUTION}

both color temperature and illuminance levels need to be adjusted to create "collaborative light". In contrast, warm but bright or dim but cold light may not elicit the desired responses.

Moreover, in field situations, the intended positive effect of dim warm light on collaboration may depend on, or be reduced or overshadowed by numerous contextual factors: environmental conditions (e.g., room temperature, air quality, window view), social variables (e.g., relationship of the negotiators), and other individual traits (e.g., stimulus screening ability; Dijkstra et al., 2008). Light also influences to what extent individuals see the facial expressions of their discussion partners (visual pathway), as well as their vigilance and attentiveness (biological pathway; Boyce, 2014). All of these aspects could be important in real negotiations.

\subsection{Conclusion}

The current studies broaden the exploration of environmental conditions that support collaborative conflict resolution strategies and suggest that the effect of light may be complex because light affects people differently depending on social orientation. The results provide support for the idea that among self-oriented individuals, dim warm light activates interdependent self-construal, which in turn promotes collaborative conflict styles. In conclusion, to facilitate collaborative conflict resolution, it may be favorable to allow individuals to view each other in a different light. 


\section{Endnotes}

${ }^{1}$ We used an estimation of power for the first study we conducted and then raised the number of participants in Study 2 by 50\%.

${ }^{2}$ We conducted all analyses using the original five conflict styles and essentially replicated the reported results. Results can be obtained from the first author.

${ }^{3}$ Unexpectedly, the bright-neutral dummy variables had a positive effect on self-construal, indicating that participants in the bright-neutral condition apparently construed themselves more interdependently than those in the other conditions. The effect may appear due to feelings of familiarity, as bright neutral light may be more frequently used or experienced as more pleasant (see also Kruithof, 1941), which could indirectly change self-construal. However, our prediction focused on the interaction between the lighting condition and the personality trait social dominance orientation. The comparison of the effects indicates a different impact of dim warm and bright neutral light on self-construal for self-interested individuals: Dim warm x SDO: $b=.90, p=.007$ vs. bright neutral x SDO: $b=-.32, p=.33$. As expected, there was only an interaction effect of dim warm light (but not other lighting conditions) with social dominance orientation.

${ }^{4}$ We thank an anonymous reviewer for pointing out this idea.

${ }^{5}$ As in Study 1, we conducted all analyses using the original five conflict styles and essentially replicated the reported results. Results can be obtained from the first author. 


\section{LIGHT AND CONFLICT RESOLUTION STRATEGIES}

\section{References}

Aron, A., Aron, E. N., \& Smollan, D. (1992). Inclusion of Other in the Self Scale and the structure of interpersonal closeness. Journal of Personality and Social Psychology, 63, 596-612. http://dx.doi.org/10.1037//0022-3514.63.4.596

Aiken, L. S., \& West, S. G. (1991). Multiple regression: Testing and interpreting interactions. Newbury Park, CA: Sage.

Ajzen, I. (1991). The theory of planned behavior. Organizational Behavior and Human Decision Processes, 50, 179-211. http://dx.doi.org/10.1016/0749-5978(91)90020-T

Altemeyer, B. (1998). The other "Authoritarian Personality". In M. P. Zanna (Hrsg.), Advances in Experimental Social Psychology (Bd. 30, S. 47-92). San Diego, CA: Academic Press.

Apenburg, E. (1986). Befindlichkeitsbeschreibung als Methode der Beanspruchungsmessung. Psychologie u. Praxis. Zeitschrift für Arbeits- und Organisationspsychologie, 30, 3-14.

Bar-Anan, Y., Liberman, N., Trope, Y., \& Algom, D. (2007). Automatic processing of psychological distance: Evidence from a Stroop task. Journal of Experimental Psychology: General, 136, 610-622. http://dx.doi.org/10.1037/0096-3445.136.4.610

Bargh, J. A., \& Shalev, I. (2011). The substitutability of physical and social warmth in Daily Life. Emotion, 12, 154-162. http://dx.doi.org/10.1037/a0023527

Baron, R. A., Rea, M. S., \& Daniels, S. G. (1992). Effects of indoor lighting (illuminance and spectral distribution) on the performance of cognitive tasks and interpersonal behaviors: The potential mediating role of positive affect. Motivation and Emotion, 16, 1-33. http://dx.doi.org/10.1007/BF00996485

Bilsky, W., \& Wülker, A. (2000). Konfliktstile: Adaptation und Erprobung des Rahim Organizational Conflict Inventory (ROCI-II). Berichte aus dem Psychologischen Institut IV, Universität Münster. 


\section{LIGHT AND CONFLICT RESOLUTION STRATEGIES}

Bing, M. N., LeBreton, J. M., Davison, H. K., Migetz, D. Z., \& James, L. R. (2007). Integrating implicit and explicit social cognitions for enhanced personality assessment: A general framework for choosing measurement and statistical methods. Organizational Research Methods, 10, 346-389. http://dx.doi.org/10.1177/1094428107301148

Biner, P. M., Butler, D. L., Fischer, A. R., \& Westergren, A. J. (1989). An arousal optimization model of lighting level preferences: An interaction of social situation and task demands. Environment and Behavior, 21, 3-16. http://dx.doi.org/10.1177/0013916589211001

Boyce, P. R. 2014. Human factors in lighting. Crc Press. London. New York.

Boyce, P. R., Veitch, J. A., Newsham, G. R., Myer, M., \& Hunter, C. (2003). Lighting quality and office work: A field simulation study (PNNL 14506). Richland, WA, USA: Pacific Northwest National Laboratory. http://doi.org/10.4224/20393390

Champoux, J. E., \& Peters,W. S. (1987). Form, effect size, and power in moderated regression analysis. Journal of Occupational Psychology, 60, 243-255. http://dx.doi.org/10.1111/j.2044-8325.1987.tb00257.x

Chanin, M.N., \& Schneer, J.A. (1984). A study of the relationship between Jungian personality dimensions and conflict-handling behavior. Human Relations, 37, 863879. http://dx.doi.org/10.1177/001872678403701006

Cohen, J., Cohen, P., West, S. G., \& Aiken, L. S. (2003). Applied multiple correlation/ regression analysis for the behavioral sciences. UK: Taylor \& Francis.

Colbert, A. E., Mount, M. K., Harter, J. K., Witt, L. A., \& Barrick, M. R. (2004). Interactive effects of personality and perceptions of the work situation on workplace deviance. Journal of Applied Psychology, 89, 599-609. http://dx.doi.org/10.1037/0021$\underline{9010.89 .4 .599}$ 


\section{LIGHT AND CONFLICT RESOLUTION STRATEGIES}

Cross, S. E., Hardin, E. E., \& Gercek-Swing, B. (2011). The what, how, why, and where of self-construal. Personality and Social Psychology Review, 15, 142-179. http://dx.doi.org/10.1177/1088868310373752

Custers, P., de Kort, Y., IJsselsteijn, W., de Kruiff, M. (2010). Lighting in retail environments: Atmosphere perception in the real world. Lighting Research and Technology, 43, 331-343. http://dx.doi.org/10.1177/1477153510377836

Derlega, V. J., Cukur, C. S., Kuang, J. C., \& Forsyth, D. R. (2002). Interdependent construal of self and the endorsement of conflict resolution strategies in interpersonal, intergroup, and international disputes. Journal of Cross-Cultural Psychology, 33, 610625. http://dx.doi.org/10.1177/0022022102238272

Dijkstra, K., Pieterse, M. E., \& Pruyn, A. T. H. (2008). Individual differences in reactions towards color in simulated healthcare environments: The role of stimulus screening ability. Journal of Environmental Psychology, 28, 268-277.

http://dx.doi.org/10.1016/j.jenvp.2008.02.007

Duckitt, J., Wagner, C., du Plessis, I., \& Birum, I. (2002). The psychological bases of ideology and prejudice: Testing a dual process model. Journal of Personality and Social Psychology, 83, 75-93. http://dx.doi.org/10.1037/0022-3514.83.1.75

Ellis, J. B., \& Wittenbaum, G. M. (2000). Relationships between self-construal and verbal promotion. Communication Research, 27, 704-722. http://dx.doi.org/10.1177/009365000027006002

Escalas, J. E., \& Bettman, J. R. (2005). Self-construal, reference groups, and brand meaning. Journal of Consumer Research, 32, 378-389. http://dx.doi.org/10.1086/497549

Evans, M. G. (1985). A Monte Carlo study of the effects of correlated method variance in moderated multiple regression analysis. Organizational Behavior and Human Decision Processes, 36, 305- 323. http://dx.doi.org/10.1016/0749-5978(85)90002-0 


\section{LIGHT AND CONFLICT RESOLUTION STRATEGIES}

Festinger, L. (1957). A Theory of Cognitive Dissonance. Stanford, CA: Stanford University Press.

Flynn, J. E. (1977). A study of subjective responses to low energy and nonuniform lighting systems. Lighting Design and Application, 7, 6-15.

Flynn, J. E. (1992). Lighting-design decisions as interventions in human visual space. In: J.L. Nasar (Ed.) Environmental Aesthetics: Theory, Research and Applications. (pp. 156170). New York: Cambridge University Press.

Friedman, R. S., Fishbach, A., Förster, J., \& Werth, L. (2003). Attentional priming effects on creativity. Creativity Research Journal, 15, 277-286. http://dx.doi.org/10.1207/S15326934CRJ152\&3_18

Funder, D. C. (1991). Global traits: A neo-Allportian approach to personality. Psychological Science, 2, 31-39.

Gardner, W. L., Gabriel, S., \& Lee, A. Y. (1999). "I" value freedom, but "we” value relationships: Self-construal priming mirrors cultural differences in judgment. Psychological Science, 10, 321-326. http://dx.doi.org/10.1111/1467-9280.00162

Gifford, R. (1988). Light, decor, arousal, comfort and communication. Journal of Environmental Psychology, 8, 177-189. http://dx.doi.org/10.1016/S0272$\underline{4944(88) 80008-2}$

Gockel, C., Kolb, P.M., Werth, L. (2014). Murder or not? Cold temperature makes criminals appear to be cold-blooded and warm temperature to be hot-headed. PLOS ONE 9, e96231. http://dx.doi.org/10.1371/journal.pone.0096231

Hayes, A. F. (2013). Introduction to mediation, moderation, and conditional process analysis. New York: Guilford.

Highhouse, S. (2009). Designing experiments that generalize. Organizational Research Methods, 12, 554-566. http://dx.doi.org/10.1177/1094428107300396 


\section{LIGHT AND CONFLICT RESOLUTION STRATEGIES}

Holland, R. W., Roeder, U. R., Brandt, A. C., \& Hannover, B. (2004). Don't stand so close to me the effects of self-construal on interpersonal closeness. Psychological Science, 15, 237-242. http://dx.doi.org/10.1111/j.0956-7976.2004.00658.x

Hu, L. T., \& Bentler, P. M. (1999). Cutoff criteria for fit indexes in covariance structure analysis: Conventional criteria versus new alternatives. Structural Equation Modeling: a Multidisciplinary Journal, 6, 1-55. http://dx.doi.org/10.1080/10705519909540118

Hygge, S., \& Knez, I. (2001). Effects of noise, heat and indoor lighting on cognitive performance and self-reported affect. Journal of Environmental Psychology, 21, 291299. http://dx.doi.org/10.1006/jevp.2001.0222

IJzerman, H., \& Semin, G. R. (2009). The thermometer of social relations: mapping social proximity on temperature. Psychological Science, 20, 1214-1220. http://dx.doi.org/10.1111/j.1467-9280.2009.02434.x

IJzerman, H., \& Semin, G. (2010). Temperature perceptions as a ground for social proximity. Journal of Experimental Social Psychology, 46, 867-873. http://dx.doi.org/10.1016/j.jesp.2010.07.015

Inagaki, T. K., \& Eisenberger, N. I. (2013). Shared neural mechanisms underlying social warmth and physical warmth. Psychological Science, 24, 2272-2280. http://dx.doi.org/10.1177/0956797613492773

Knez, I. (1995). Effects of indoor lighting on mood and cognition. Journal of Environmental Psychology, 15, 39-51. http://dx.doi.org/10.1016/0272-4944(95)90013-6

Knez, I. (2001). Effects of colour of light on nonvisual psychological processes. Journal of Environmental Psychology, 21, 201-208. http://dx.doi.org/10.1006/jevp.2000.0198 Kobayashi, S., Inui, M., \& Nakamura, Y. (2001). Preferred illuminance non-uniformity of interior ambient lighting. Journal of Light and Visual Environment, 25, 64-75. http://dx.doi.org/10.2150/jlve.25.2_64 


\section{LIGHT AND CONFLICT RESOLUTION STRATEGIES}

Kolb, P., Gockel, C., \& Werth, L. (2012). The effects of temperature on service employees' customer orientation: an experimental approach. Ergonomics, 55, 621-635. http://dx.doi.org/10.1080/00140139.2012.659763

Kruithof, A.A. (1941). Tubular luminescence lamps for general illumination. Philips Technical Review 6, 65-96.

Kuhlman, D., \& Marshello, A. (1975). Individual differences in game motivation as moderators of preprogrammed strategy effects in prisoner's dilemma. Journal of Personality and Social Psychology, 32, 922-931. http://dx.doi.org/10.1037/0022-3514.32.5.922

Kuijsters, A., Redi, J., de Ruyter, B., Seuntiëns, P., \& Heynderickx, I. (2015). Affective ambiences created with lighting for older people. Lighting Research and Technology, 47, 859-875. http://dx.doi.org/10.1177/1477153514560423

Lalwani, A. K., \& Shavitt, S. (2009). The "me” I claim to be: Cultural self-construal elicits self-presentational goal pursuit. Journal of Personality and Social Psychology, 97, 88102. http://dx.doi.org/10.1037/a0014100

Lee, R. M., Draper, M., \& Lee, S. (2001). Social connectedness, dysfunctional interpersonal behaviors, and psychological distress: Testing a mediator model. Journal of Counseling Psychology, 48, 310-318. http://dx.doi.org/10.1037/0022-0167.48.3.310

Mandel, N. (2003). Shifting selves and decision making: The effects of self-construal priming on consumer risk-taking. Journal of Consumer Research, 30, 30-40. http://dx.doi.org/10.1086/374700

Markus, H. R., \& Kitayama, S. (1991). Culture and the self: Implications for cognition, emotion, and motivation. Psychological Review, 98, 224-253. http://dx.doi.org/10.1037/0033-295X.98.2.224

McClelland, G. H., \& Judd, C. M. (1993). Statistical difficulties of detecting interactions and 


\section{LIGHT AND CONFLICT RESOLUTION STRATEGIES}

moderator effects. Psychological Bulletin, 114, 376-390.

http://dx.doi.org/10.1037/0033-2909.114.2.376

McCloughan, C. L. B., Aspinall, P. A., \& Webb, R. S. (1999). The impact of lighting on mood. Lighting Research and Technology, 31, 81-88. http://dx.doi.org/10.1177/096032719903100302

Nitsch J. R. (1976). Die Eigenzustandsskala (EZ-Skala) - Ein Verfahren zur hierarchisch mehrdimensionalen Befindlichkeitsskalierung. In: I.U.J.R. Nitsch (Ed.). Beanspruchung im Sport. Beiträge zur psychologischen Analyse sportlicher Leistungssituationen, 81-102. Bad Homburg, Germany, Limpert.

Oetzel, J.G. (1998). The effects of self-construals and ethnicity on self reported conflict styles. Communication Reports, 11, 133-144. http://dx.doi.org/10.1080/08934219809367695

Oetzel, J., Meares, M., Myers, K. K., \& Lara, E. (2003). Interpersonal conflict in organizations: Explaining conflict styles via face negotiation theory. Communication Research Reports, 20, 106-115. http://dx.doi.org/10.1080/08824090309388806

Okken, V., van Rompay, T., \& Pruyn, A. (2013). Room to move on spatial constraints and self-disclosure during intimate conversations. Environment and Behavior, 45, 737760. http://dx.doi.org/10.1177/0013916512444780

Park, N. K., Pae, J. Y., \& Meneely, J. (2010). Cultural preferences in hotel guestroom lighting design. Journal of Interior Design, 36, 21-34. http://dx.doi.org/10.1111/j.1939-

\section{$\underline{1668.2010 .01046 . x}$}

Pratto, F., Sidanius, J., \& Levin, S. (2006). Social dominance theory and the dynamics of intergroup relations: Taking stock and looking forward. European Review of Social Psychology, 17, 271-320. http://dx.doi.org/10.1080/10463280601055772

Preacher, K. J., Zyphur, M. J., \& Zhang, Z. (2010). A general multilevel SEM framework for 


\section{LIGHT AND CONFLICT RESOLUTION STRATEGIES}

assessing multilevel mediation. Psychological Methods, 15, 209-233. http://dx.doi.org/10.1037/a0020141

Pruitt, D. G. (1983). Strategic choice in negotiation. American Behavioral Scientist, 27, 167194. http://dx.doi.org/10.1177/000276483027002005

Pruitt, D. G. (1998). Social conflict. In: D.T.Gilbert, S.T.Fiske, G.Lindzey (Eds), The handbook of social psychology (Vols. 1 and 2, 4th ed. pp. 470-503). New York, NY, US: McGraw-Hill.

Psenicka, C., \& Rahim, M. A. (1989). Integrative and distributive dimensions of styles of handling interpersonal conflict and bargaining outcome. In M. A. Rahim (Ed.), Managing conflict: An interdisciplinary approach (pp. 33-40). New York:

Putnam, L. L., \& Wilson, C. E. (1982). Communicative strategies in organizational conflicts: Reliability and validity of a measurement scale. In M. Burgoon (Ed.), Communication Yearbook, (Vol. 6, pp. 629-652). Beverly Hills, CA: Sage.

Rahim, M. A. (1983). A measure of styles of handling interpersonal conflict. Academy of Management Journal, 26, 368-376. http://dx.doi.org/10.2307/255985

Rahim, M. A., \& Bonoma, T. V, (1979). Managing organizational conflict: A model for diagnosis and intervention. Psychological Reports, 44, 1323-1344. http://dx.doi.org/10.2466/pr0.1979.44.3c.1323

Rauthmann, J. F., Kappes, M., \& Lanzinger, J. (2014). Shrouded in the veil of darkness: Machiavellians but not narcissists and psychopaths profit from darker weather in courtship. Personality and Individual Differences, 67, 57-63. http://dx.doi.org/10.1016/j.paid.2014.01.020

Ross, L., \& Stittinger, C. (1991). Barriers to conflict resolution. In K. J. Arrow, M. H. Mnookin, L. Ross, A. Tversky, R. B. Wilson (Eds.) Negotiation Journal (Vol.7, pp 389-404). New York. London. 


\section{LIGHT AND CONFLICT RESOLUTION STRATEGIES}

aan het Rot, M., Moskowitz, D. S., \& Young, S. N. (2008). Exposure to bright light is associated with positive social interaction and good mood over short time periods: A naturalistic study in mildly seasonal people. Journal of Psychiatric Research, 42, 311319. http://dx.doi.org/10.1016/j.jpsychires.2006.11.010

Sidanius, J. (1993). The psychology of group conflict and the dynamics of oppression: A social dominance perspective. In S. Iyengar \& W. McGuire (Eds.), Current approaches to political psychology (pp. 173-211). Durham, NC: Duke University Press.

Steidle, A., Hanke, E., \& Werth, L. (2013). In the dark we cooperate: The situated nature of procedural embodiment. Social Cognition, 31, 275-300. http://dx.doi.org/10.1521/soco.2013.31.2.275

Steidle, A., \& Werth, L. (2013). Freedom from constraints: Darkness and dim illumination promote creativity. Journal of Environmental Psychology, 35, 67-80. http://dx.doi.org/10.1016/j.jenvp.2013.05.003

Sundstrom, E. (1975). An experimental study of crowding: Effects of room size, intrusion, and goal blocking on nonverbal behavior, self-disclosure, and self-reported stress. Journal of Personality and Social Psychology, 32, 645-654. http://dx.doi.org/10.1037/0022-3514.32.4.645

Thau, S., Pitesa, M., \& Pillutla, M. (2014). Experiments in organizational behavior. In Laboratory Experiments in the Social Sciences, M. Webster, J. Sell (Eds.), Academic Press, 433 - 447.

Theiss, E. (2000). Beleuchtungstechnik: neue Technologien der Innen- und Außenbeleuchtung. Oldenbourg Industrieverlag.

Thomas, K. W. (1976). Conflict and conflict management. In M. D. Dunnette (Ed.). Handbook of Industrial and Organizational Psychology (pp. 889-935). Chicago: Rand 


\section{LIGHT AND CONFLICT RESOLUTION STRATEGIES}

McNally.

Ting-Toomey, S. (1988). Intercultural conflict styles: A face-negotiation theory. In Y.Y. Kim \& W. Gudykunst (Eds.). Theories in Intercultural Communication (pp. 213-235). Newbury Park, CA: Sage.

Ting-Toomey, S., Oetzel, J. G., \& Yee-Jung, K. (2001). Self-construal types and conflict management styles. Communication Reports, 14, 87-104. http://dx.doi.org/10.1080/08934210109367741

Tjosvold, D. (1990). The goal interdependence approach to communication in conflict: An organizational study. In M. A. Rahim (Ed.), Theory and Research in Conflict Management (pp. 15-27). New York: Praeger.

Triandis, H. C. (1989). The self and social behavior in differing cultural contexts. Psychological Review, 96, 506-520. http://dx.doi.org/10.1037/0033-295X.96.3.506

Varnum, M. E., Grossmann, I., Kitayama, S., \& Nisbett, R. E. (2010). The origin of cultural differences in cognition the social orientation hypothesis. Current directions in psychological science, 19, 9-13. http://dx.doi.org/10.1177/0963721409359301

Veitch, J. A., Newsham, G. R., Boyce, P. R., \& Jones, C. C. (2008). Lighting appraisal, wellbeing, and performance in open-plan offices: A linked mechanisms approach. Lighting Research and Technology, 40, 133-151. http://dx.doi.org/10.1177/1477153507086279.

Vogels I.M.L.C., de Vries M., \& van Erp, T.A.M. (2008). Effect of coloured light on atmosphere perception: Proceedings of the AIC Interim Meeting, Swedish Colour Centre Foundation. Stockholm: AIC, pp.15-18.

Volkema, R. J., \& Bergmann, T. J. (1995). Conflict styles as indicators of behavioral patterns in interpersonal conflicts. The Journal of Social Psychology, 135, 5-15. http://dx.doi.org/10.1080/00224545.1995.9711395

Zhong, C.-B., Bohns, V. K., \& Gino, F. (2010). Good lamps are the best police: Darkness 


\section{LIGHT AND CONFLICT RESOLUTION STRATEGIES}

increases dishonesty and self-interested behavior. Psychological Science, 21, 311314. http://dx.doi.org/10.1177/0956797609360754

Zhong, C. B., \& Leonardelli, G. J. (2008). Cold and lonely: does social exclusion literally feel cold? Psychological Science, 19, 838-842. http://dx.doi.org/10.1111/j.1467$\underline{9280.2008 .02165 . x}$ 


\section{LIGHT AND CONFLICT RESOLUTION STRATEGIES}

Table 1

Factor Loadings and Variance Explained for Principal Components Analyses in Study 1

\begin{tabular}{lcccc}
\hline & Cooperating factor & Obliging factor & Dominating factor & Avoiding factor \\
\hline Compromising item 1 & .76 & .06 & -.32 & .16 \\
Compromising item 2 & .65 & .26 & -.34 & -.06 \\
Compromising item 3 & .73 & .07 & .08 & .03 \\
Integrating item 1 & .47 & -.13 & -.47 & .40 \\
Integrating item 2 & .64 & .09 & .03 & -.43 \\
Integrating item 3 & .80 & .15 & -.15 & .12 \\
Obliging item 1 & -.02 & .56 & -.26 & .09 \\
Obliging item 2 & .10 & .69 & -.13 & -.06 \\
Obliging item 3 & .33 & .67 & .06 & .13 \\
Dominating item 1 & -.09 & -.16 & .71 & -.14 \\
Dominating item 2 & -.12 & -.02 & .88 & .07 \\
Dominating item 3 & -.12 & -.28 & .73 & .21 \\
Avoiding item 1 & .03 & -.22 & .16 & .59 \\
Avoiding item 2 & .18 & .39 & -.10 & .57 \\
Avoiding item 3 & -.05 & .28 & -.03 & .74 \\
Variance explained $(\%)$ & 19.9 & 11.6 & 15.9 & 11.4 \\
\hline
\end{tabular}




\section{LIGHT AND CONFLICT RESOLUTION STRATEGIES}

Table 2

Descriptive Statistics and Correlations in Study 1

\begin{tabular}{|c|c|c|c|c|c|c|c|c|c|c|c|c|c|c|c|c|c|}
\hline \multirow[t]{2}{*}{ Variables } & \multirow[b]{2}{*}{ Range } & \multicolumn{2}{|c|}{$\begin{array}{c}\text { Dim warm } \\
\text { condition } \\
\end{array}$} & \multicolumn{2}{|c|}{$\begin{array}{c}\text { Dim neutral } \\
\text { condition }\end{array}$} & \multicolumn{2}{|c|}{$\begin{array}{l}\text { Bright warm } \\
\text { condition }\end{array}$} & \multicolumn{2}{|c|}{$\begin{array}{c}\text { Bright neutral } \\
\text { condition } \\
\end{array}$} & \multirow[t]{2}{*}{ Mean } & \multirow[t]{2}{*}{$S D$} & \multirow[t]{2}{*}{1} & \multirow[t]{2}{*}{2} & \multirow[t]{2}{*}{3} & \multirow[t]{2}{*}{4} & \multirow[t]{2}{*}{5} & \multirow[t]{2}{*}{6} \\
\hline & & Mean & $S D$ & Mean & $S D$ & Mean & $S D$ & Mean & $S D$ & & & & & & & & \\
\hline $\begin{array}{l}\text { Situative self- } \\
\text { construal }\end{array}$ & $1-7$ & 3.20 & 0.91 & 2.62 & 1.44 & 2.64 & 0.99 & 3.23 & 1.52 & 2.94 & 1.28 & - & & & & & \\
\hline 2. $\mathrm{SDO}$ & $1-7$ & 3.14 & 0.75 & 2.07 & 0.95 & 3.05 & 1.08 & 3.33 & 0.79 & 3.13 & 0.89 & -.14 & .84 & & & & \\
\hline 3. Cooperating & $1-5$ & 3.81 & 0.61 & 3.59 & 0.66 & 3.48 & 0.61 & 3.73 & 0.76 & 3.66 & 0.67 & $.51 * *$ & -.06 & .79 & & & \\
\hline 4. Obliging & $1-5$ & 2.54 & 0.70 & 2.53 & 0.59 & 2.51 & 0.70 & 2.34 & 0.48 & 2.47 & 0.56 & $.20 *$ & -.08 & $.32 * *$ & .46 & & \\
\hline 5. Dominating & $1-5$ & 3.95 & 0.80 & 3.92 & 0.73 & 4.04 & 0.63 & 3.84 & 0.82 & 3.93 & 0.75 & $-.25 *$ & .09 & $-.38 * *$ & $-.21 *$ & .75 & \\
\hline 6. Avoiding & $1-5$ & 2.89 & 0.86 & 3.05 & 0.73 & 2.84 & 0.71 & 2.81 & 0.68 & 2.90 & 0.74 & -.01 & -.04 & .16 & $.25 *$ & -.08 & .54 \\
\hline
\end{tabular}

Note. $N=100-105 ;$ SDO = Social Dominance Orientation. The numbers in bold on the diagonal are reliability coefficients. To facilitate the interpretation of the values of the conflict styles, raw mean values are presented. For correlations, we used standardized values of conflict styles. $* p<.05, * * p<.01$ 


\section{LIGHT AND CONFLICT RESOLUTION STRATEGIES}

Table 3

Hierarchical Regressions on Situative Self-Construal and on Conflict Resolution Strategies in Study 1

\begin{tabular}{|c|c|c|c|c|c|c|c|c|c|c|c|c|}
\hline \multirow{3}{*}{$\begin{array}{r}\text { Variable } \\
\text { Bright neutral }\end{array}$} & \multicolumn{4}{|c|}{ Situative self-construal } & \multirow{2}{*}{\multicolumn{2}{|c|}{$\begin{array}{c}\text { Cooperating } \\
\text { Model } 3\end{array}$}} & \multirow{2}{*}{\multicolumn{2}{|c|}{$\begin{array}{l}\text { Obliging } \\
\text { Model } 4\end{array}$}} & \multirow{2}{*}{\multicolumn{2}{|c|}{$\begin{array}{c}\text { Dominating } \\
\text { Model } 5\end{array}$}} & \multirow{2}{*}{\multicolumn{2}{|c|}{$\frac{\text { Avoiding }}{\text { Model } 6}$}} \\
\hline & \multicolumn{2}{|c|}{ Model 1} & \multicolumn{2}{|c|}{ Model 2} & & & & & & & & \\
\hline & $.59^{*}$ & $(.34)$ & $.74 *$ & $(.33)$ & -.09 & $(.24)$ & -.45 & $(.26)$ & .06 & $(.27)$ & -.26 & $(.28)$ \\
\hline Bright warm & .00 & $(.36)$ & .03 & (.34) & -.19 & $(.24)$ & -.05 & $(.27)$ & .18 & $(.27)$ & -.24 & $(.29)$ \\
\hline Dim warm & $.56^{\dagger}$ & (.36) & $.62 *$ & $(.35)$ & -.02 & $(.25)$ & -.07 & $(.28)$ & .21 & $(.28)$ & -.13 & $(.29)$ \\
\hline SDO & & & $-.18^{\dagger}$ & (.13) & & & & & & & & \\
\hline SDO x dim warm & & & $.90^{* *}$ & (.36) & & & & & & & & \\
\hline $\begin{array}{l}\text { Situative self- } \\
\text { construal }\end{array}$ & & & & & $.39 * *$ & $(.07)$ & $.18^{*}$ & $(.08)$ & $-.19 *$ & $(.08)$ & .003 & .08 \\
\hline $\begin{array}{c}R^{2} \\
\Delta R^{2}\end{array}$ & & $5 \dagger$ & $\begin{array}{l}.1 \\
.05\end{array}$ & & & & & $8^{\dagger}$ & & & & \\
\hline
\end{tabular}

Notes. $N=100-105$. Missing values were excluded via pairwise deletion. Values are unstandardized regression coefficients; standard error estimates are in parentheses. All lower-order terms used in interactions were centered prior to analysis. SDO = Social Dominance Orientation. ${ }^{\dagger} p$ $<.10 ; * p<.05 ; * * p<.01$. 


\section{LIGHT AND CONFLICT RESOLUTION STRATEGIES}

Table 4

The Results of Moderated Mediation Analyses in Study 1

\begin{tabular}{|c|c|c|c|c|c|c|c|}
\hline & SDO & $\begin{array}{l}\text { Indirect } \\
\text { effect }(S E)\end{array}$ & $95 \% C I$ & $90 \% C I$ & $\begin{array}{l}\text { Index of moderated } \\
\text { mediation }(S E)\end{array}$ & $95 \% C I$ & $90 \% C I$ \\
\hline $\begin{array}{l}\text { Cooperating } \\
\text { via situative } \\
\text { self-construal }\end{array}$ & $\begin{array}{l}\text { High } \\
\text { Medium } \\
\text { Low }\end{array}$ & $\begin{array}{l}.54(.21)^{* *} \\
.28(16)^{* *} \\
.02(.18) \\
\end{array}$ & $\begin{array}{c}.20,1.04] \\
{[.04, .67]} \\
{[-.28, .43]} \\
\end{array}$ & $\begin{array}{l}{[.25, .95]} \\
{[.07, .59]} \\
{[-.25, .36]}\end{array}$ & $.29(.13)$ & {$[.05 ; .57]$} & {$[.10 ; .53]$} \\
\hline $\begin{array}{l}\text { Obliging via } \\
\text { situative self- } \\
\text { construal }\end{array}$ & $\begin{array}{l}\text { High } \\
\text { Medium } \\
\text { Low }\end{array}$ & $\begin{array}{l}.25(.12)^{* *} \\
.11(.08)^{* *} \\
-.03(.09)\end{array}$ & $\begin{array}{c}{[.06, .57]} \\
{[.002, .32]} \\
{[-.22, .13]}\end{array}$ & $\begin{array}{l}{[.09, .51]} \\
{[.01, .28]} \\
{[-.19, .09]}\end{array}$ & $.16(.08)$ & {$[.03 ; .37]$} & {$[.05 ; .35]$} \\
\hline
\end{tabular}

Notes. $N=100-105 . \mathrm{SDO}=$ Social Dominance Orientation. *Indirect effect is significant at $90 \%$ CI; **Indirect effect is significant at $95 \%$ CI . 


\section{LIGHT AND CONFLICT RESOLUTION STRATEGIES}

Table 5

Descriptive Statistics and Correlations in Study 2

\begin{tabular}{|c|c|c|c|c|c|c|c|c|c|c|c|c|c|c|c|c|c|c|}
\hline \multirow[t]{2}{*}{ Variables } & \multirow[b]{2}{*}{ Range } & \multicolumn{2}{|c|}{$\begin{array}{l}\text { Dim warm } \\
\text { condition }\end{array}$} & \multicolumn{2}{|c|}{$\begin{array}{l}\text { Dim cold } \\
\text { condition }\end{array}$} & \multicolumn{2}{|c|}{$\begin{array}{l}\text { Bright warm } \\
\text { condition }\end{array}$} & \multicolumn{2}{|c|}{$\begin{array}{l}\text { Bright cold } \\
\text { condition }\end{array}$} & \multirow[t]{2}{*}{ Mean } & \multirow[t]{2}{*}{$S D$} & \multirow[t]{2}{*}{1} & \multirow[t]{2}{*}{2} & \multirow[t]{2}{*}{3} & \multirow[t]{2}{*}{4} & \multirow[t]{2}{*}{5} & \multirow[t]{2}{*}{6} & \multirow[t]{2}{*}{7} \\
\hline & & Mean & $S D$ & Mean & $S D$ & Mean & $S D$ & Mean & $S D$ & & & & & & & & & \\
\hline $\begin{array}{l}\text { Situative self- } \\
\text { construal }\end{array}$ & $1-7$ & 2.37 & 1.49 & 2.14 & 1.07 & 2.21 & 1.17 & 2.33 & 1.19 & 2.26 & 1.23 & - & & & & & & \\
\hline 2. SDO & $1-7$ & 2.93 & 1.16 & 2.43 & 0.64 & 3.08 & 0.98 & 3.06 & 1.15 & 2.88 & 1.03 & .07 & .88 & & & & & \\
\hline 3. TSC & $1-7$ & 4.55 & 0.63 & 4.62 & 0.59 & 4.68 & 0.57 & 4.63 & 0.62 & 4.62 & 0.60 & .09 & $.16^{\dagger}$ & .56 & & & & \\
\hline 4. Cooperating & $1-5$ & 3.93 & 0.62 & 3.78 & 0.71 & 3.89 & 0.64 & 3.90 & 0.60 & 3.88 & 0.64 & $.19 *$ & $-.29 * *$ & $.27 * *$ & .75 & & & \\
\hline 5. Obliging & $1-5$ & 2.50 & 0.52 & 2.58 & 0.69 & 2.60 & 0.60 & 2.53 & 0.53 & 2.55 & 0.58 & $.18^{*}$ & -.06 & $.28 * *$ & $.37 * *$ & .45 & & \\
\hline 6. Dominating & $1-5$ & 3.62 & 0.64 & 3.79 & 0.79 & 3.73 & 0.66 & 3.74 & 0.67 & 3.72 & 0.68 & -.06 & .12 & -.09 & $-.24 * *$ & $-.28 * *$ & .63 & \\
\hline 7. Avoiding & $1-5$ & 2.84 & 0.91 & 3.05 & 0.83 & 2.97 & 0.78 & 3.05 & 0.79 & 2.97 & 0.82 & .06 & -.05 & $.17 *$ & -.01 & $.30 * *$ & .12 & .49 \\
\hline
\end{tabular}

Note. $N=150-152$. Missing values were excluded via pairwise deletion. The numbers in bold on the diagonal are reliability coefficients. SDO =

Social Dominance Orientation, TSC $=$ Trait interdependent Self-Construal. To facilitate the interpretation of the values of the conflict styles, raw mean values are presented. For correlations, we used standardized values of conflict styles. ${ }^{\dagger} p<.10 ; * p<.05 ; * * p<.01$. 


\section{LIGHT AND CONFLICT RESOLUTION STRATEGIES}

Table 6

Hierarchical Regressions on Situative Self-Construal and on Conflict Resolution Strategies in Study 2

\begin{tabular}{|c|c|c|c|c|c|c|c|c|c|c|c|c|c|c|c|c|}
\hline \multirow{3}{*}{$\begin{array}{l}\text { Variable } \\
\text { Bright cold }\end{array}$} & \multicolumn{8}{|c|}{ Situative self-construal } & \multirow{2}{*}{\multicolumn{2}{|c|}{$\frac{\text { Cooperating }}{\text { Model } 3}$}} & \multirow{2}{*}{\multicolumn{2}{|c|}{$\begin{array}{l}\text { Obliging } \\
\text { Model } 4\end{array}$}} & \multirow{2}{*}{\multicolumn{2}{|c|}{$\begin{array}{c}\text { Dominating } \\
\text { Model } 5\end{array}$}} & \multirow{2}{*}{\multicolumn{2}{|c|}{$\begin{array}{c}\text { Avoiding } \\
\text { Model } 6\end{array}$}} \\
\hline & \multicolumn{2}{|c|}{ Model 1} & \multicolumn{2}{|c|}{ Model 2a } & \multicolumn{2}{|c|}{ Model 2b } & \multicolumn{2}{|c|}{ Model 2c } & & & & & & & & \\
\hline & .19 & $(.29)$ & .22 & $(.30)$ & .19 & $(.28)$ & .21 & $(.29)$ & .08 & $(.23)$ & -.21 & $(.22)$ & -.09 & $(.23)$ & .04 & $(.23)$ \\
\hline Bright warm & .07 & $(.29)$ & .10 & $(.30)$ & .04 & $(.28)$ & .06 & $(.29)$ & .19 & $(.23)$ & .04 & $(.22)$ & -.08 & $(.23)$ & -.07 & $(.23)$ \\
\hline Dim warm & .23 & $(.29)$ & .24 & $(.29)$ & .20 & $(.29)$ & .21 & $(.29)$ & .18 & $(.23)$ & -.14 & $(.23)$ & -.22 & $(.23)$ & -.24 & $(.23)$ \\
\hline SDO & & & .05 & $(.10)$ & & & .05 & $(.10)$ & & & & & & & & \\
\hline SDO x dim warm & & & $.39 *$ & $(.21)$ & & & $.31^{\dagger}$ & $(.22)$ & & & & & & & & \\
\hline TSC & & & & & .21 & $(.17)$ & $.25^{\dagger}$ & $(.17)$ & & & & & & & & \\
\hline TSC $x$ dim warm & & & & & $-.88 * *$ & $(.37)$ & $-.69 *$ & $(.39)$ & & & & & & & & \\
\hline $\begin{array}{l}\text { Situative self- } \\
\text { construal }\end{array}$ & & & & & & & & & $.15^{*}$ & $(.06)$ & $.15^{*}$ & $(.06)$ & -.04 & $(.07)$ & .05 & .07 \\
\hline $\begin{array}{c}R^{2} \\
\Delta R^{2} \\
\end{array}$ & & 01 & & & & & & & & & & $4^{\dagger}$ & & 1 & & 02 \\
\hline
\end{tabular}

Note. $N=151-152$. Missing values were excluded via pairwise deletion. Values are unstandardized regression coefficients; standard error

estimates are in parentheses. All lower-order terms used in interactions were centered prior to analysis. SDO = Social Dominance Orientation,

TSC $=$ Trait Interdependent Self-Construal. ${ }^{\dagger} p<.10 ;{ }^{*} p<.05 ; * * p<.01$. 


\section{LIGHT AND CONFLICT RESOLUTION STRATEGIES}

Table 7

The Results of Moderated Mediation Analyses in Study 2

\begin{tabular}{|c|c|c|c|c|c|c|c|}
\hline & SDO & $\begin{array}{l}\text { Indirect } \\
\text { effect }(S E)\end{array}$ & $95 \% C I$ & $90 \% C I$ & $\begin{array}{l}\text { Index of moderated } \\
\text { mediation }(S E)\end{array}$ & $95 \% C I$ & $90 \% C I$ \\
\hline \multirow{3}{*}{$\begin{array}{l}\text { Cooperating } \\
\text { via situative } \\
\text { self-construal }\end{array}$} & High & $.09(.08)^{*}$ & {$[-.02, .34]$} & {$[.002, .29]$} & \multirow{3}{*}{$.06(.05)$} & \multirow{3}{*}[-.01;.19]{} & \multirow{3}{*}[.003;.17]{} \\
\hline & Medium & $.03(.05)$ & {$[-.04, .17]$} & {$[-.02, .14]$} & & & \\
\hline & Low & $-.02(.06)$ & {$[-.17, .07]$} & {$[-.14, .06]$} & & & \\
\hline \multirow{4}{*}{$\begin{array}{l}\text { Obliging via } \\
\text { situative self- } \\
\text { construal }\end{array}$} & High & $.09(.08)^{*}$ & {$[-.01, .35]$} & {$[.004, .30]$} & \multirow{3}{*}{$.06(.05)$} & \multirow{3}{*}[-.007;.21]{} & \multirow{3}{*}[.003;.17]{} \\
\hline & Medium & $.04(.05)$ & {$[-.04, .17]$} & {$[-.02$.15] } & & & \\
\hline & Low & $-.02(.06)$ & {$[-.17, .07]$} & {$[-.14, .05]$} & & & \\
\hline & TSC & & & & & & \\
\hline \multirow{3}{*}{$\begin{array}{l}\text { Cooperating } \\
\text { via situative } \\
\text { self-construal }\end{array}$} & High & $-.05(.06)$ & {$[-.22, .04]$} & {$[-.18, .02]$} & \multirow{3}{*}{$-.13(.08)$} & \multirow{3}{*}[-.37;-.01]{} & \multirow{3}{*}[-.32;-.03]{} \\
\hline & Medium & $.03(.05)$ & {$[-.05, .15]$} & {$[-.03, .13]$} & & & \\
\hline & Low & $.11(08)^{*}$ & {$[-.0002, .33]$} & {$[.02, .29]$} & & & \\
\hline \multirow{3}{*}{$\begin{array}{l}\text { Obliging via } \\
\text { situative self- } \\
\text { construal }\end{array}$} & High & $.05(.06)$ & {$[-.21, .04]$} & {$[-.18, .02]$} & \multirow{3}{*}{$-.13(.08)$} & \multirow{3}{*}[-.34;-.02]{} & \multirow{3}{*}[-.30;-.04]{} \\
\hline & Medium & $.03(.05)$ & {$[-.04, .15]$} & {$[-.02, .13]$} & & & \\
\hline & Low & $.11(07)^{* *}$ & {$[.01, .31]$} & {$[.03, .28]$} & & & \\
\hline
\end{tabular}

Notes. $N=151-152 . \mathrm{SDO}=$ Social Dominance Orientation, TSC $=$ Trait Interdependent Self-Construal. *Indirect effect is significant at $90 \%$ CI;

**Indirect effect is significant at $95 \% C I$. 


\section{LIGHT AND CONFLICT RESOLUTION STRATEGIES}

Figure 1

Hypothesized Model

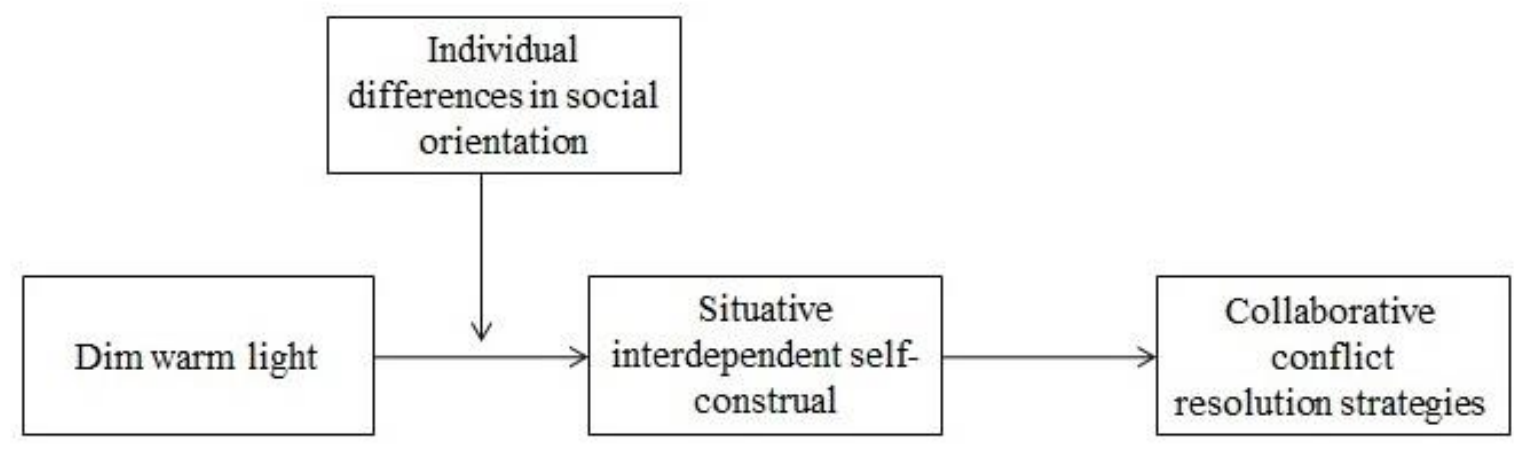




\section{LIGHT AND CONFLICT RESOLUTION STRATEGIES}

Figure 2

Lighting Conditions in Study 1

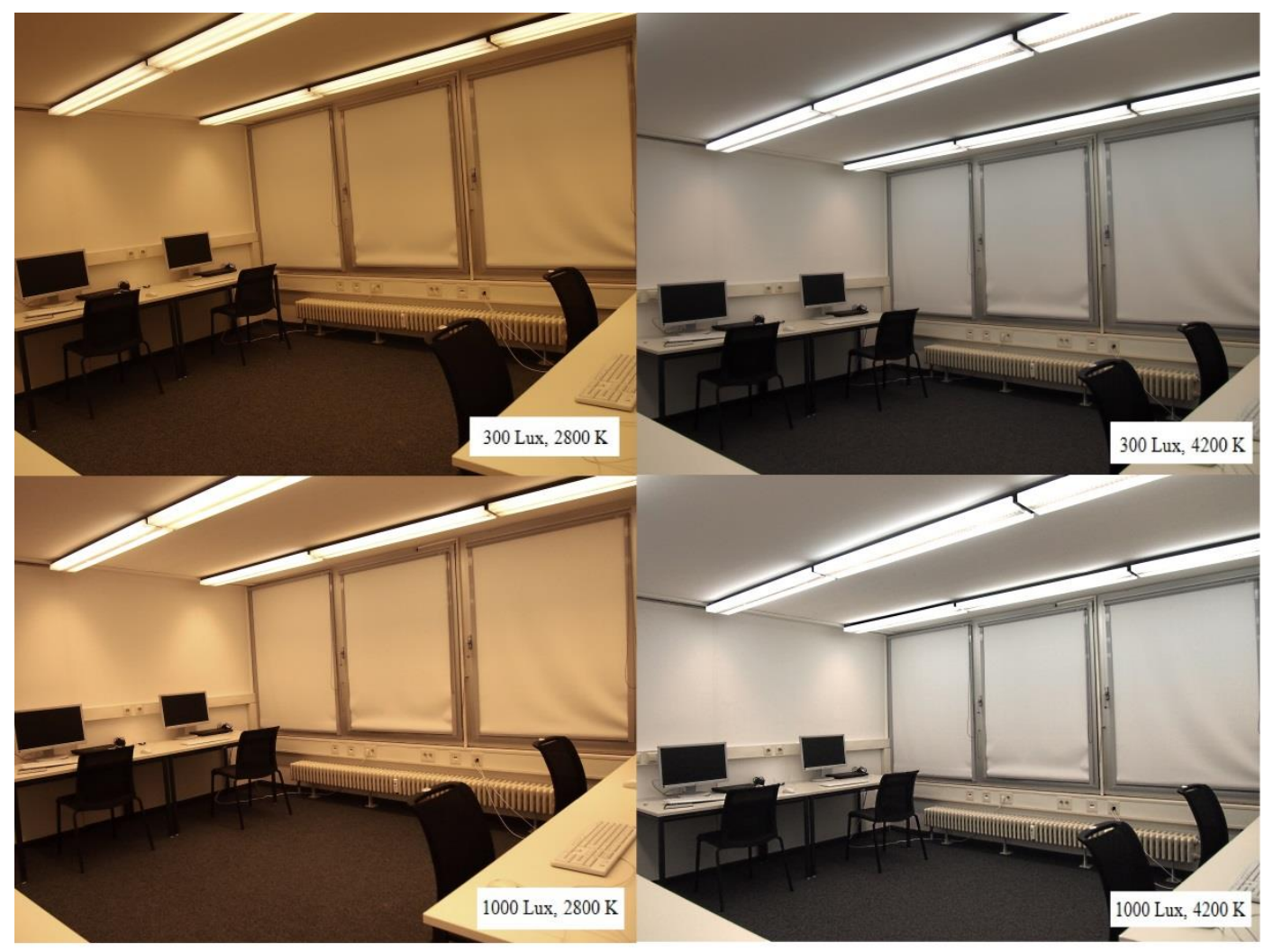




\section{LIGHT AND CONFLICT RESOLUTION STRATEGIES}

Figure 3

Interactive Effects of Lighting Condition and Social Dominance Orientation on Situative Self-

Construal in Study 1

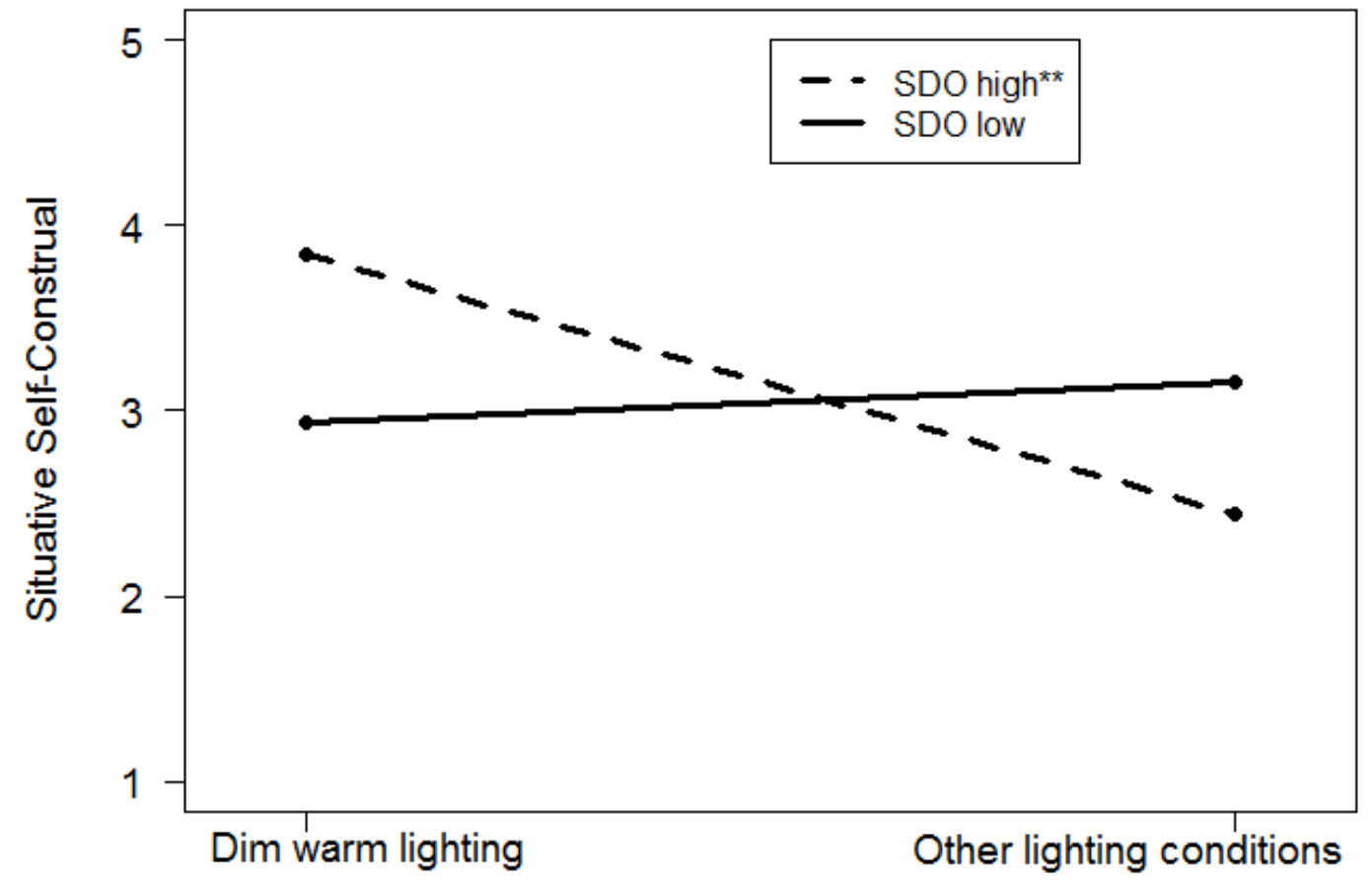

Note. $N=105 . \mathrm{SDO}=$ Social Dominance Orientation; Values are predicted values from

Model 2 in Table 3; The lines are included to ease the interpretation of the results

$* * p($ slope $)<.01$. 


\section{LIGHT AND CONFLICT RESOLUTION STRATEGIES}

Figure 4

Lighting Conditions in Study 2

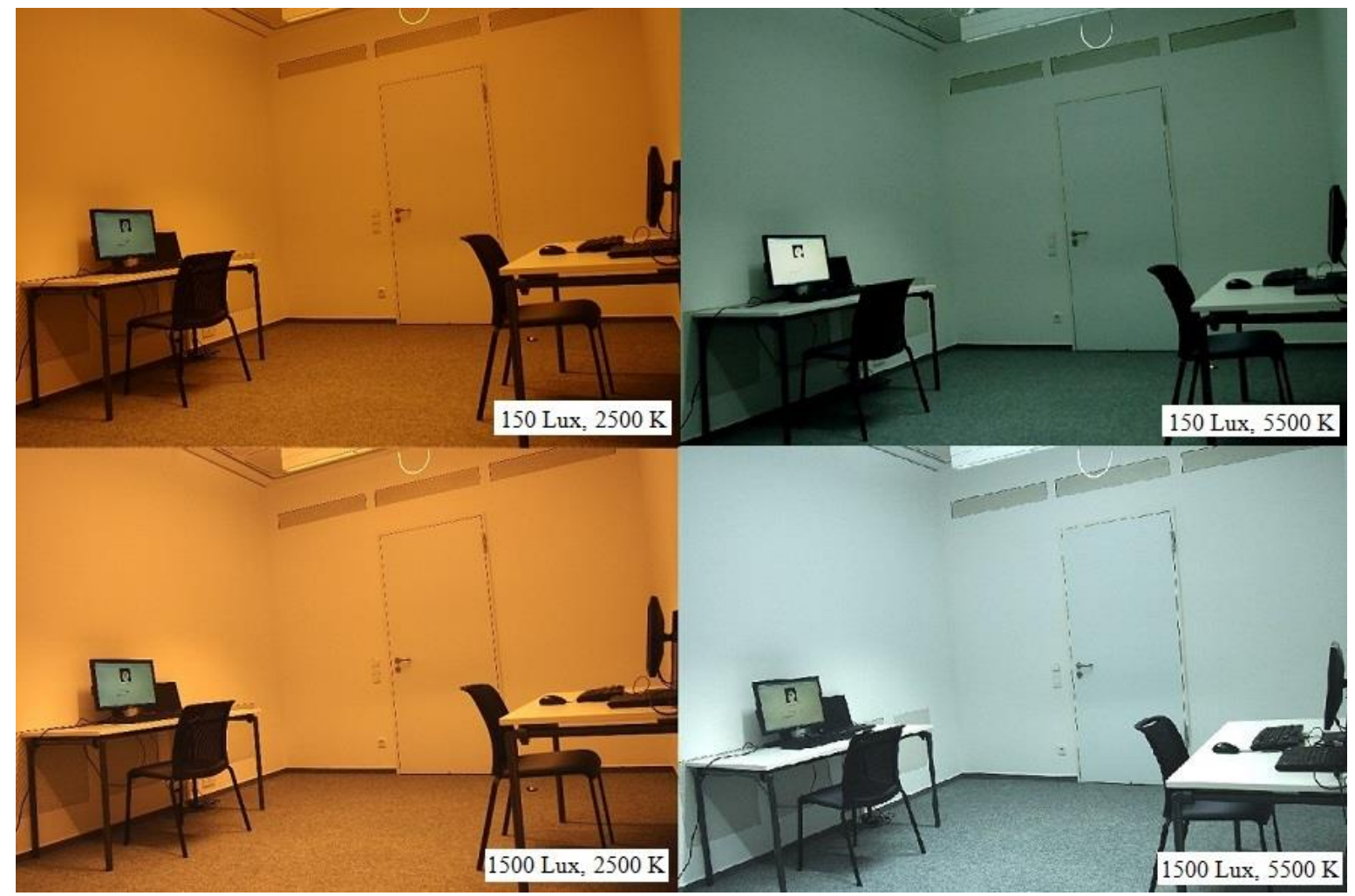




\section{LIGHT AND CONFLICT RESOLUTION STRATEGIES}

Figure 5

Interactive Effects of Lighting Condition and Social Dominance Orientation on Situative Self-

Construal in Study 2

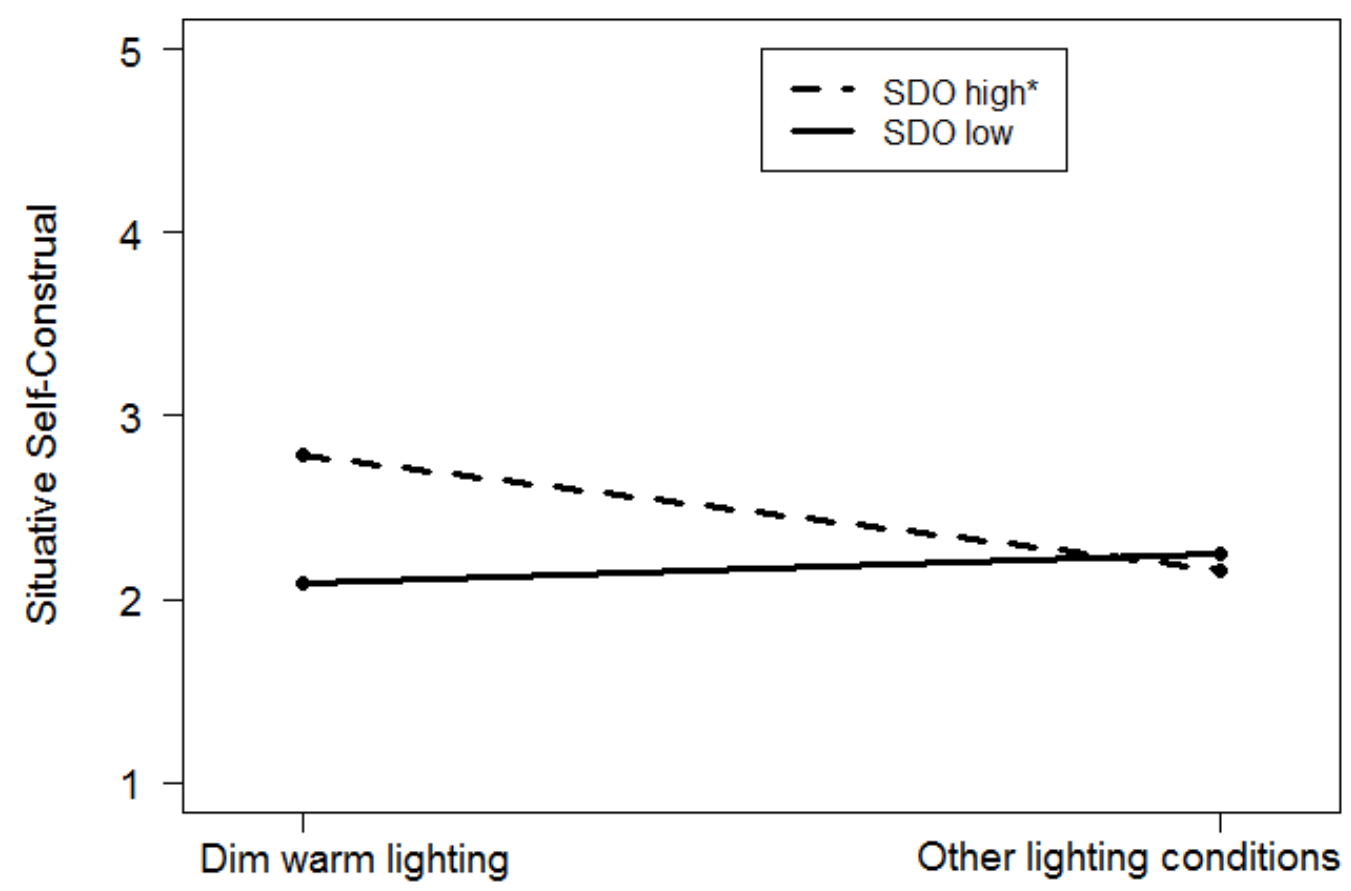

Note. $N=152 . \mathrm{SDO}=$ Social Dominance Orientation; Values are predicted values from

Model 2a in Table 4; The lines are included to ease the interpretation of the results $* p($ slope $)<.05$. 


\section{LIGHT AND CONFLICT RESOLUTION STRATEGIES}

Figure 6

Interactive Effects of Lighting Condition and Trait Self-Construal on Situative Self-Construal

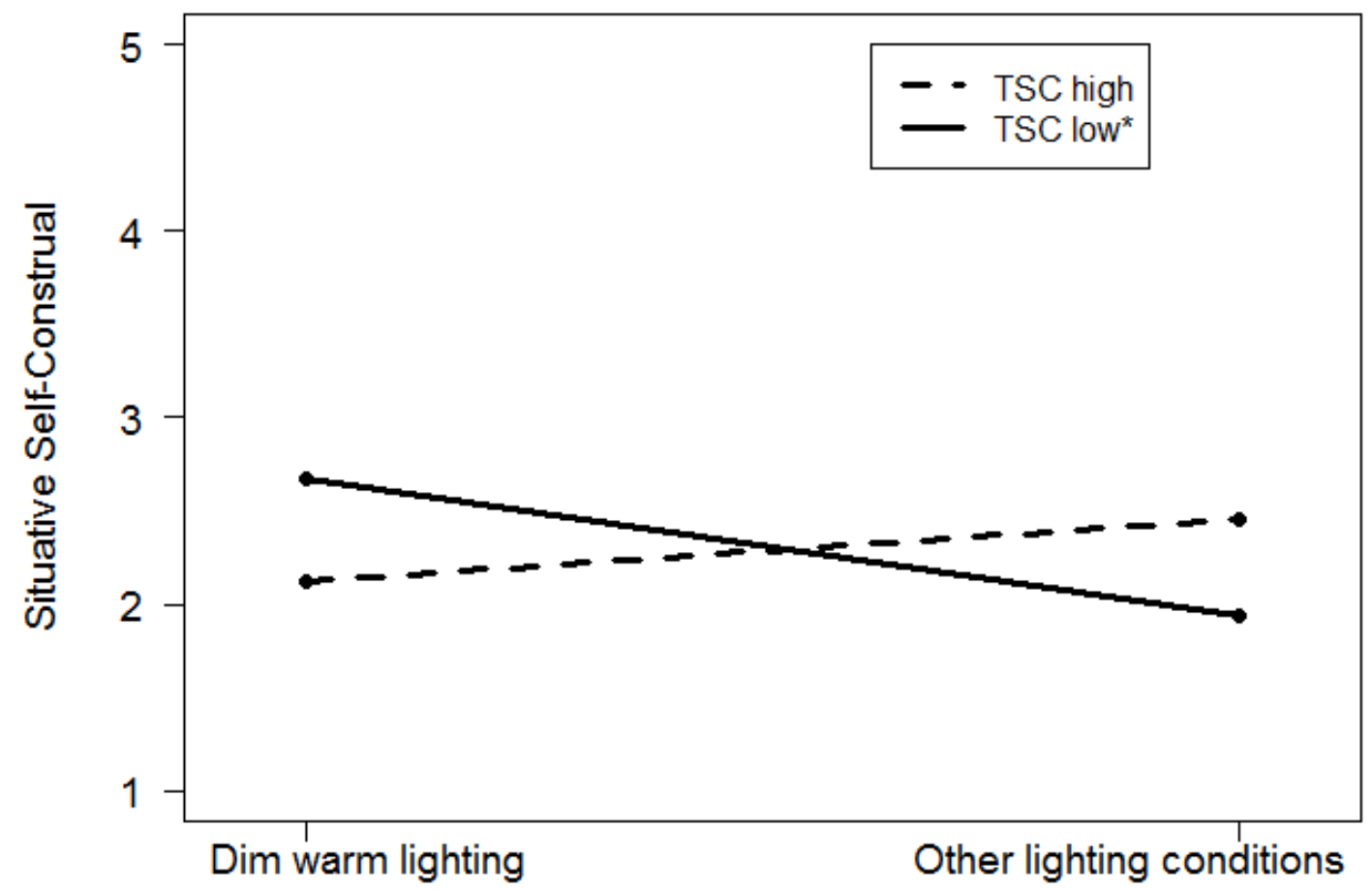

Note. $N=152$. TSC $=$ Trait Interdependent Self-Construal; Values are predicted values from

Model $2 \mathrm{~b}$ in Table 4; The lines are included to ease the interpretation of the results

$* p($ slope $)<.05$. 